\title{
WestVirginiaUniversity
}

THE RESEARCH REPOSITORY @ WVU

Graduate Theses, Dissertations, and Problem Reports

2006

\section{The impact of relative permeability on type curves for coalbed methane reservoirs}

Sunil Lakshminarayanan

West Virginia University

Follow this and additional works at: https://researchrepository.wvu.edu/etd

\section{Recommended Citation}

Lakshminarayanan, Sunil, "The impact of relative permeability on type curves for coalbed methane reservoirs" (2006). Graduate Theses, Dissertations, and Problem Reports. 3249.

https://researchrepository.wvu.edu/etd/3249

This Thesis is protected by copyright and/or related rights. It has been brought to you by the The Research Repository @ WVU with permission from the rights-holder(s). You are free to use this Thesis in any way that is permitted by the copyright and related rights legislation that applies to your use. For other uses you must obtain permission from the rights-holder(s) directly, unless additional rights are indicated by a Creative Commons license in the record and/ or on the work itself. This Thesis has been accepted for inclusion in WVU Graduate Theses, Dissertations, and Problem Reports collection by an authorized administrator of The Research Repository @ WVU. For more information, please contact researchrepository@mail.wvu.edu. 


\section{THE IMPACT OF RELATIVE PERMEABILITY ON TYPE CURVES FOR COALBED METHANE RESERVOIRS}

Sunil L akshminarayanan

Thesis Submitted to the

College of Engineering and $M$ ineral Resources

At W est Virginia University

In partial fulfillments of the requirements

For the degree of

M aster of Science

In

Petroleum and Natural G as E ngineering

Ilkin Bilgesu, Ph.D.

Samuel A meri, M.S

Kashy Aminian, PhD, Committee Chairperson

Department of Petroleum and Natural Gas E ngineering

M organtown, West Virginia

2006 


\section{ABSTRACT \\ THE IMPACT OF RELATIVE PERMEABILITY ON TYPE CURVES FOR COALBED METHANE RESERVOIRS}

\section{Sunil L akshminarayanan}

Coalbed methane (CBM) is considered an unconventional gas resource produced from coal seams usually with low permeability at shallow depths. Analyzing the production performance in CBM reservoirs is challenging, especially at the early stages of recovery. Most of the small producers in the Appalachian Basin cannot afford personnel or meet economical requirements involved in the use of the numerical simulator to evaluate CBM reservoirs. Production type curves are an excellent tool for predicting the performance of CBM reservoirs. A set of type curves have been previously developed for horizontal and vertical wells in CBM reservoirs. The relative permeability characteristics have significant impact on the gas and water production due to the two-phase flow condition at the early stages of production. The impact of relative permeability on these type curves have been researched in this study.

The values of relative permeability in coal bed methane reservoirs primarily depends upon 3 constants, which are $\mathrm{n} \square, \mathrm{m} \square$ and $\mathrm{K}$. Using the relative permeability values from 4 different samples of coal, the range values for the three constants were obtained and the effect of these constants on the production type curves of gas and water were studied. It was concluded that both the gas and water production type curves were minimally affected by the variation of $\mathrm{K}$. The effect of $\mathrm{m} \square$ was more influential in affecting the gas production type curves and the effect of $\mathrm{n} \square$ influenced the water type curves more. Also, a correlation among peak gas rate and constants governing relative permeability was developed. The correlation was validated and it showed accurate results with an error less than $10 \%$. 


\section{ACKNOWLEDGEMENTS}

I would like to express my sincere gratitude to professor, Dr. Kashy Aminian, for guiding me and giving me a chance to work under him during the course of my graduate program. Your support, patience and belief has made possible the culmination of my degree

I would also like to thank Professor Sam Ameri for his constant encouragement and motivation during my stay at West Virginia University. I also appreciate your participation and enthusiasm to be part of my committee.

I would like to thank Dr. Ilkin Bilgesu for his participation in my committee.

I would like to thank Ms. Beverly Matheny for her prompt work, assistance and enthusiasm, which helped me every semester in the department.

Special thanks to Amol Bhavsar and Kazim Ali Malik for being a good friends and great co-workers. Your invaluable help has helped in every step of my research.

Thanks to my friends and roomates Arvind, Abishek, Karthik, and Hari for helping me with encouragement and words of confidence at times of distress

I would like to thank all my friends back in India for inspiring me on every step I took towards my career.

I dedicate my work to my parents and my brother, who have stood by my side at every point in life. Mom and Dad, thank you for everything in life. I wouldn】t have achieved so much without your presence.

Finally, I would like to thank the almighty for bringing me to this world with these wonderful people around. 


\section{TABLE OF CONTENTS}

ABSTRACT.

ii

ACKNOWLEDGEMENTS

iii

TABLE OF CONTENTS

ii

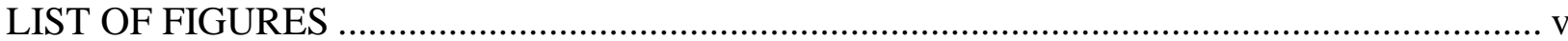

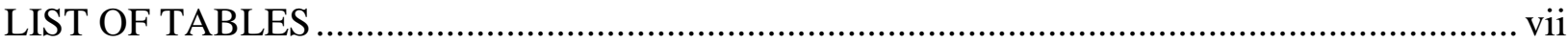

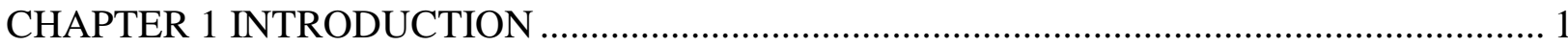

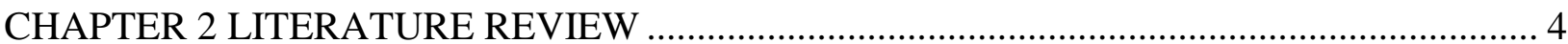

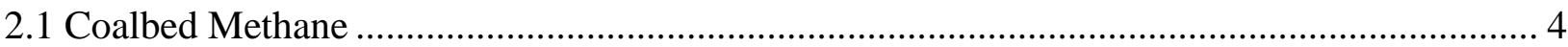

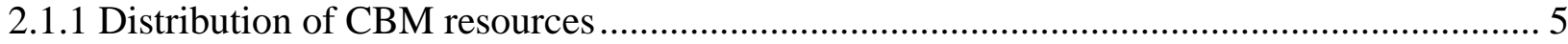

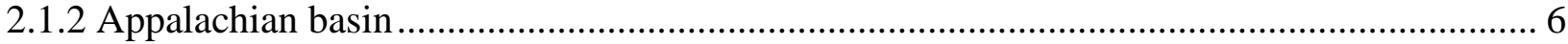

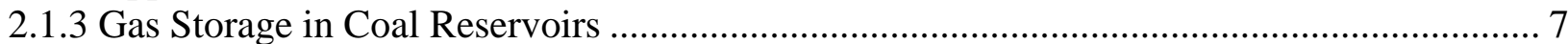

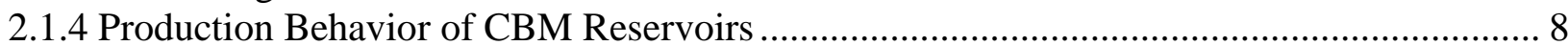

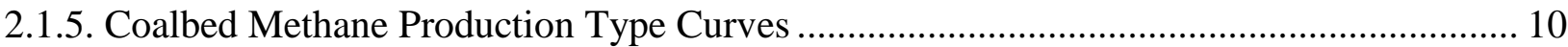

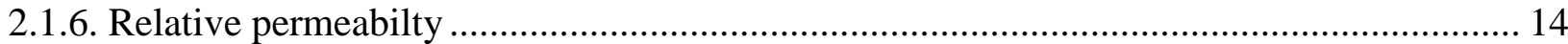

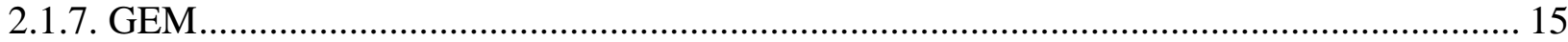

CHAPTER 3 OBJECTIVE AND METHODOLOGY …................................................... 18

3.1 Development of a base model for Coalbed methane production in Northern

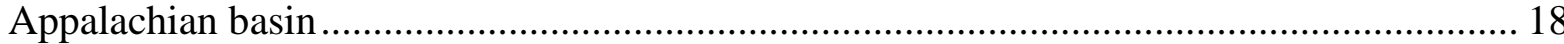

3.2 Evaluating the Impact of relative permeabilty on production type curves.......................... 20

3.3 Developing a correlation for the peak production rate for gas and the constants

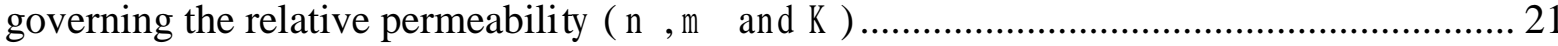

3.4 Verification of the type curves to forecast production.................................................. 22

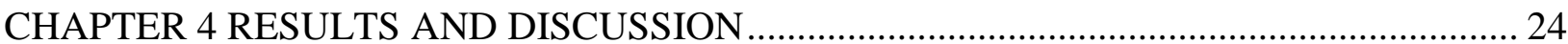

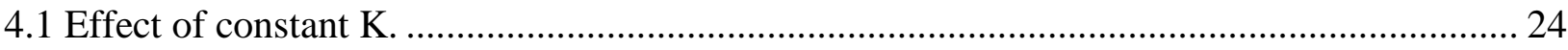

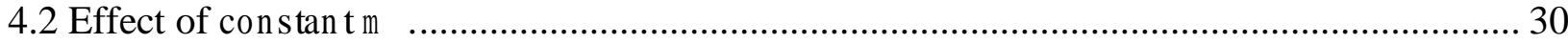

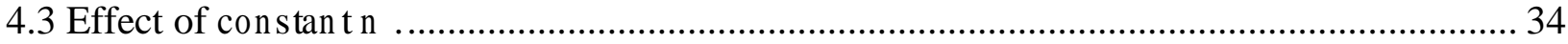

CHAPTER 5 CONCLUSIONS AND RECOMMENDATIONS ............................................ 42

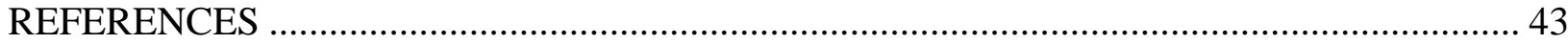




\section{LIST OF FIGURES}

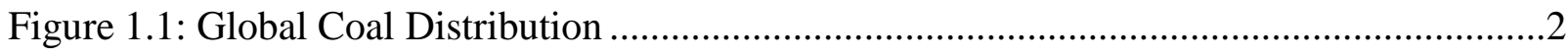

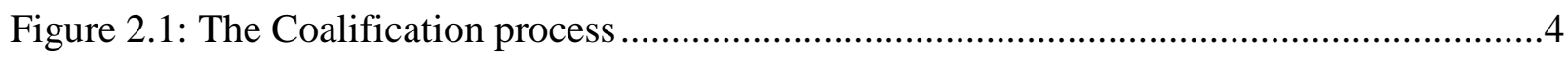

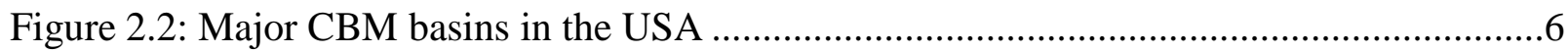

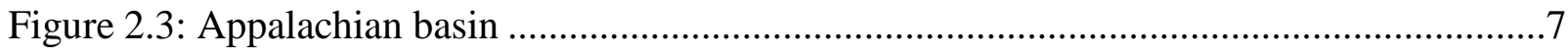

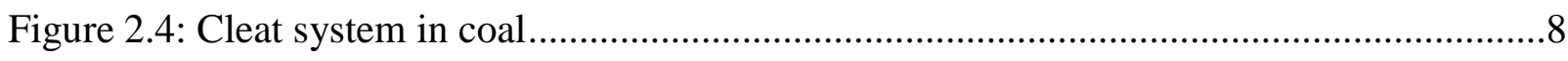

Figure 2.5: Production curve for a coal bed methane reservoir ..........................................9

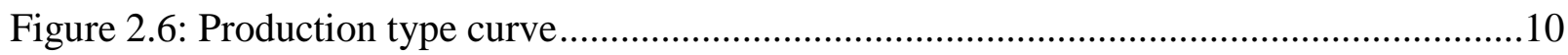

Figure 2.7: Effect of skin factor on CBM production type curves ........................................13

Figure 2.8: Effect of Langmuir pressure on CBM production type curves ............................13

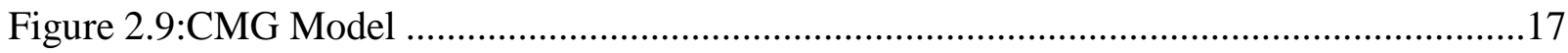

Figure 3.1: 2-D view of reservoir model being used ....................................................19

Figure 4.1: Relative permeability curves for $\mathrm{K}=0.7(\mathrm{n} \square=1.5, \mathrm{~m} \square=1)$..................................25

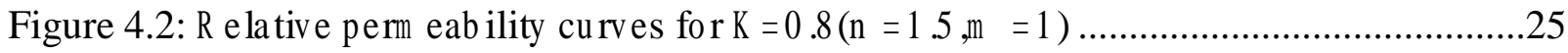

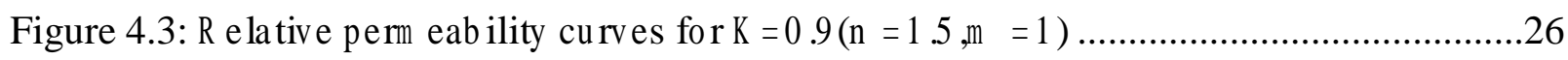

Figure 4.4: Relative permeability curves for $\mathrm{K}=1(\mathrm{n} \rrbracket=1.5, \mathrm{~m} \rrbracket=1)$...................................2.

Figure 4.5: Cartesian curve of $\mathrm{q}_{\mathrm{gd}}$ versus $\mathrm{t}_{\mathrm{gd}}$ to study the effect of $\mathrm{K}$.................................27

Figure 4.6: Logarithmic curve of $\mathrm{q}_{\mathrm{gd}}$ versus $\mathrm{t}_{\mathrm{gd}}$ to study the effect of $\mathrm{K}$................................28

Figure 4.7: Cartesian curve of $\mathrm{q}_{\mathrm{wd}}$ versus $\mathrm{t}_{\mathrm{wd}}$ to study the effect of $\mathrm{K}$................................29

Figure 4.8: Logarithmic curve of $\mathrm{q}_{\mathrm{wd}}$ versus $\mathrm{t}_{\mathrm{wd}}$ to study the effect of $\mathrm{K}$..............................29

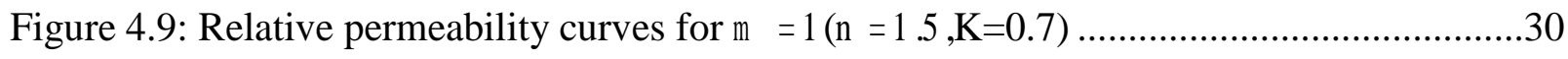

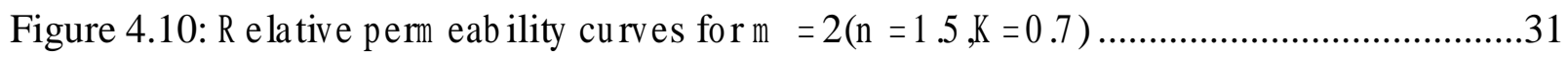

Figure 4.11: Relative permeability curves for $\mathrm{m} \square=3(\mathrm{n} \rrbracket=1.5, \mathrm{~K}=0.7)$....................................32

Figure 4.12: Cartesian curve of qgd versus tgd to study the effect of $\mathrm{m}[$................................32

Figure 4.13: Logarithmic curve of qgd versus tgd to study the effect of $\mathrm{m} \square$...........................33

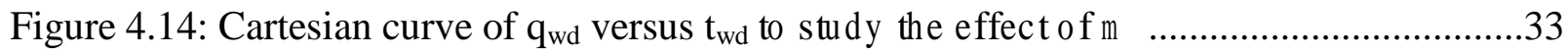

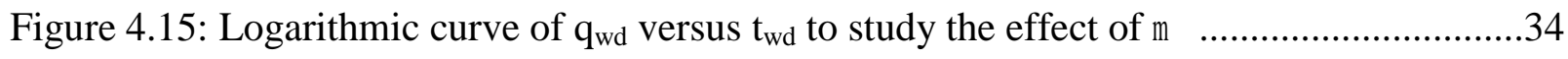

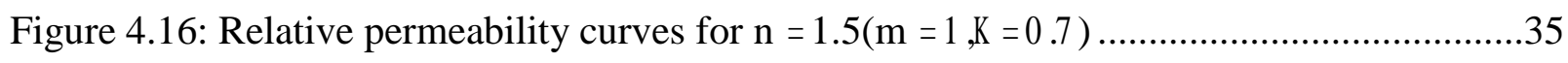

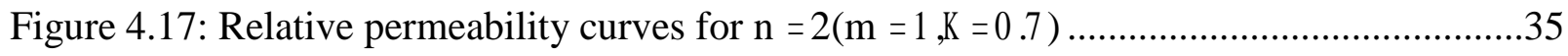

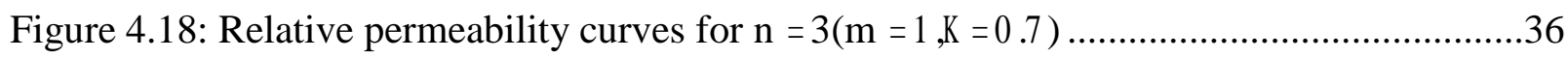




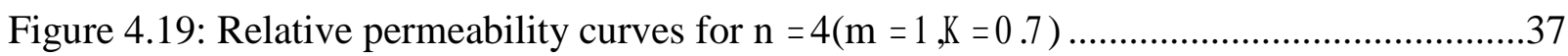

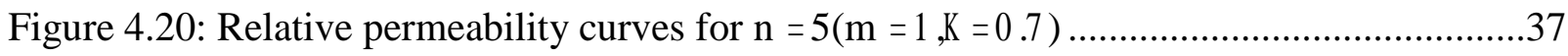

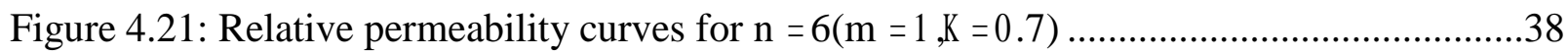

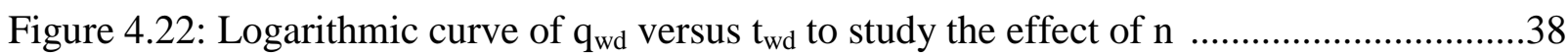

Figure 4.23: Logarithmic curve of $\mathrm{q}_{\mathrm{gd}}$ versus $\mathrm{t}_{\mathrm{gd}}$ to study the effect of $\mathrm{n} \square$...............................39

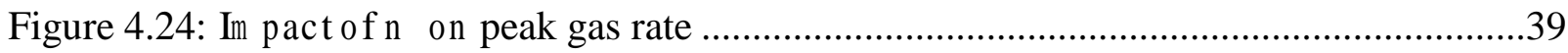

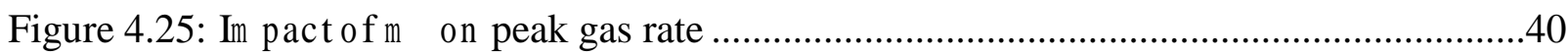

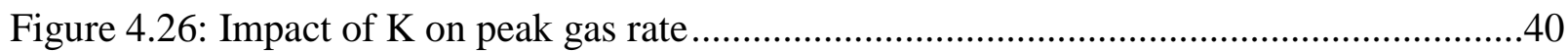

Figure 4.27: Comparison of the predicted model with the original model ............................41 


\section{LIST OF TABLES}

Table 3.1: Reservoir parameters used to develop the Base Model .......................................19

Table 3.2: Values of $\mathrm{n} \square, \mathrm{m} \square$ and $\mathrm{K}$ from each sample ......................................................20

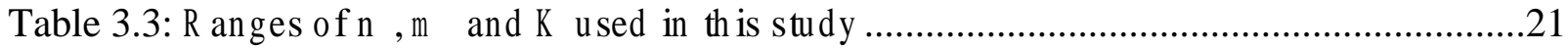

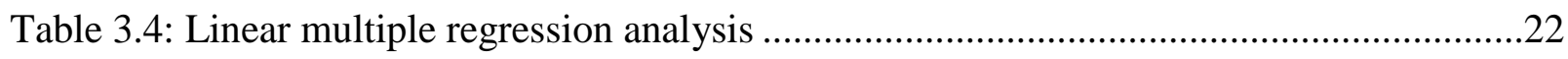

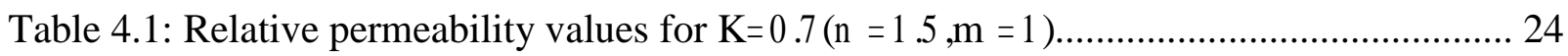

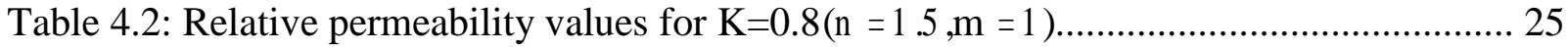

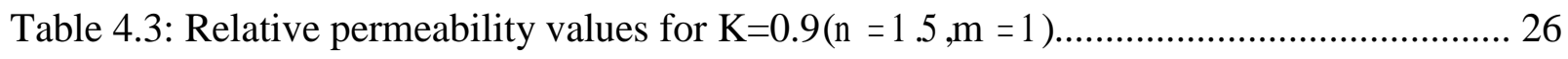

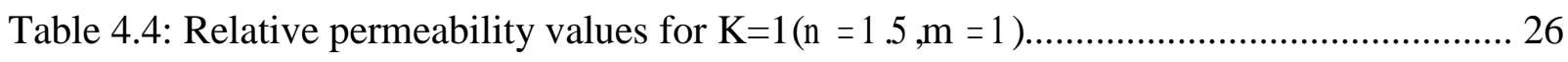

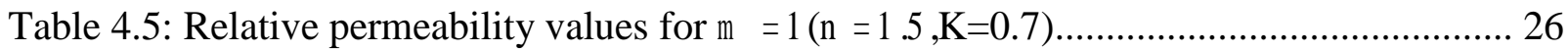

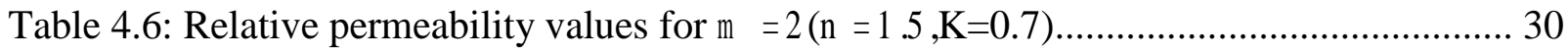

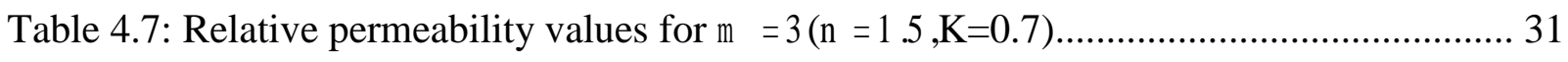

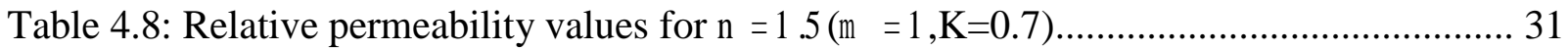

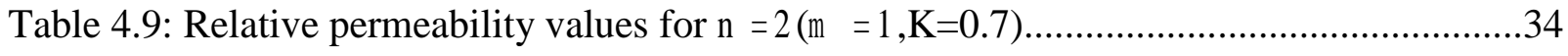

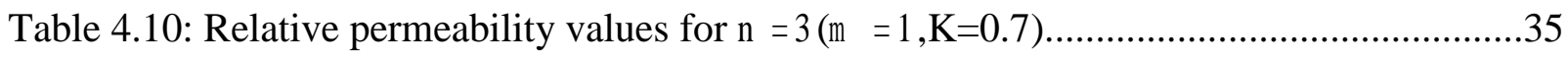

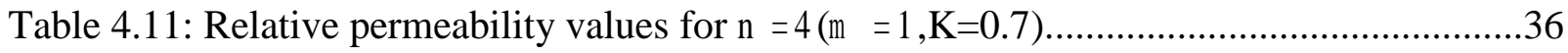

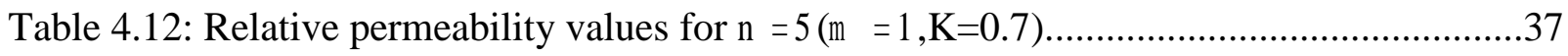

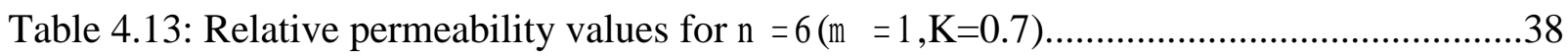




\section{CHAPTER 1 \\ INTRODUCTION}

The primary component of natural gas happens to be „Methane[. Methane is produced when organic material is geologically turned into coal. When the coal and methane conversion process occurs such that the coal is saturated with water and methane is trapped within the coal, the result is "coal bed methane."(CBM $)^{1}$. With the current energy crisis and relatively high fuel prices, increased attention has been put on development of CBM.

Preliminary worldwide CBM resources are estimated to range between 5,800 and 24,215 Tcf. North Americals resources range between 951 to 4,383 Tcf. The production and use of CBM in the United States has steadily progressed in the last 15 years due to the discovery of new sources. CBM accounts for $9 \%$ of the total US gas production. ${ }^{2}$

The major coal resources exist in 69 countries. The world coal consumption is around 5800 million short tons annually, out of which $75 \%$ is used for electricity generation. The regions including India and China use 1800 million short tons. This figure is forecasted to increase to 3000 million short tons by the year $2025^{5}$. The USA consumes about 1100 short tons of coal every year, using $90 \%$ of it for electricity. Coal is the fastest growing energy source in the world, with coal use increasing by $25 \%$ for the three-year period ending in December $2004^{6}$

35 of the major coal countries have some CBM activity. Figure 1.1 shows the major sectors of coal distribution over the globe. The largest potential resources, which also have the largest degree of uncertainty, are in the former Soviet Union with 4,000 to 16,116 Tcf, whereas South America and Europe range from 15 to $32 \mathrm{Tcf}$ and 161 and 269 Tcf, respectively. Africa ranges between 27 and 55 Tcf; the Middle East has no CBM resources. CBM resources of the Asia Pacific region, which includes China, ranges from 646 to 3,360 Tcf. $^{3}$ 


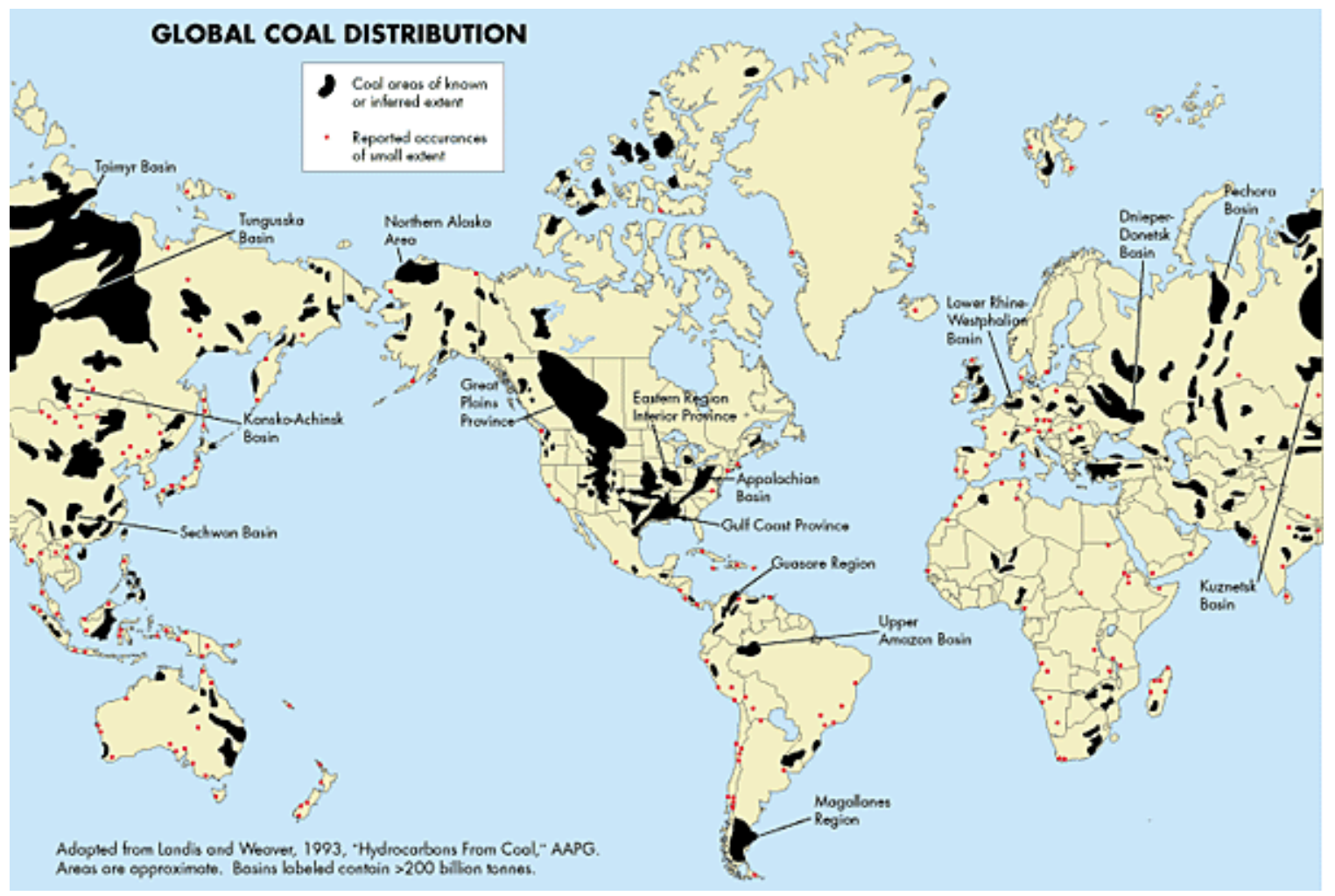

Figure 1.1. G lobal C oal Distribution.

The Appalachian basin accounts for nearly $10 \%$ of the US CBM resources. But, the development and increase of CBM production in the Appalachian basin is hindered due to the lack of scientific and user friendly tools that help in development of CBM resources ${ }^{8}$.

Coalbed methane production behavior is complex and difficult to predict at the early stages of the recovery. CBM reservoirs differ from conventional reservoirs in several aspects. Unlike conventional gas reservoirs, coal is both the reservoir rock and the source rock for methane ${ }^{9}$. CBM reservoirs are characterized by dual porosity systems: macropores and micropores. The macropores also known as cleats constitute the natural fractures common to all coal seams. Micropores, or the matrix, contain the vast majority of the gas. 
The cleats are usually filled with water. In order for gas to be released from the coal, its partial pressure must be reduced, and this is accomplished by removing water from the coalbed $^{10}$. During this dewatering process, the gas desorbs from the coal, the gas rate increases and the water saturation decreases. The water production declines rapidly until the gas rate reaches the peak value and water saturation approaches the irreducible water saturation. After the peak gas rate is achieved, the behavior of CBM reservoirs becomes similar to conventional reservoirs.

Production decline curves are usually used by reservoir engineers in order to predict well performance. But since the behavior of CBM reservoirs are complex compared to conventional reservoirs, the use of a numeric simulator is the best way to predict the CBM production behavior ${ }^{8}$.

Reservoir simulators might sometimes be very expensive and small producers would not be able to afford running a simulator. Also, operating a simulator requires in-depth knowledge and detailed data to get accurate results. Considering these factors, running a simulator might not be the best option.

Hence, in order to develop a simple and yet a reliable to tool to forecast the production in a CBM reservoir with good accuracy, it was taken upon to develop type curves for both gas and water production. 


\section{CHAPTER 2 \\ LITERATURE REVIEW}

\section{1) Coalbed methane}

Coalbed methane is natural gas or methane $\left(\mathrm{CH}_{4}\right)$ that occurs in coal beds and has been generated during the conversion of plant material to coal by the process known as coalification $^{11}$.

During coalification, plant material that accumulated and was preserved in ancient swamps and bogs at rates fast enough to prevent decay (oxidation) begins to compact upon burial. The material is first converted to peat as much of the water in the original material is expelled. As the temperature increases with further burial, ever-increasing ranks of coal form, starting with lignite, followed by sub-bituminous coal and bituminous coal. If the heat (and pressure) is great enough, anthracite (the highest rank of coal) forms. Methane attributed to bacterial activity, (Biogenic methane) is first to form. When the temperature exceeds that in which bacteria can live, methane attributed to heating (Thermogenic methane) starts to form ${ }^{11}$. Figure 2.1 shows the diagrammatic representation of the Coalification process.

\section{The Coalification Process (Simplified)}
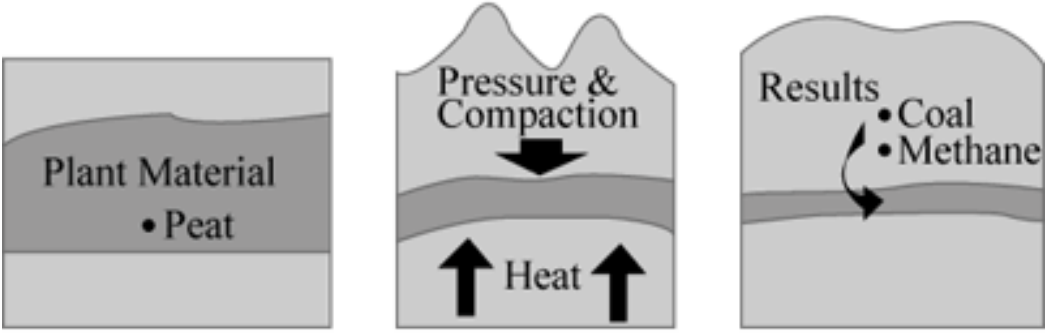

Time (millions of years)

Figure 2.1 Coalification process

At these different stages of coalification, various hydrocarbons (primarily methane), along with carbon dioxide, nitrogen, and water, are released. Increased temperatures throughout burial drive off volatile matter. The coalification process can stop at any time, depending on geologic conditions, leaving what we see today as varying ranks of coal. 
Much of the methane generated by the coalification process escapes to the surface or migrates into adjacent reservoir or other rocks, but a portion is trapped within the coal itself, primarily adsorbed on or absorbed within micropores of the coal.

Prior to 1980, coalbed methane was considered to be more of a nuisance than a resource. In 1980, U.S passed a law, which provided tax credits to producers of unconventional fuels, such as coalbed methane. This provision was aimed at increasing the nation\s energy security. The credit, which ranged from 40 cents to one dollar per thousand cubic feet of gas, produced a flurry of coalbed methane development in the mid-1980s and early 1990s. The tax credit was available for coalbed methane produced from wells drilled after December 31, 1979 and before January 1, 1993, and may be claimed through the end of $2002^{12}$.

The production and use of CBM in the United States has steadily progressed in the last 15 years due to the discovery of new sources. CBM accounts for $9 \%$ of the total US gas production $^{2}$.

\subsubsection{Distribution of CBM resources}

The largest known concentration (56\%) of CBM in the US is in the Rocky Mountains of Wyoming, Utah, New Mexico, Colorado, and Montana. Large deposits of CBM are known and being developed in the Powder River Basin, San Juan Basin, Uinta Basin, Piceance Basin, and Raton Basin (Figure 2.2). The total gas in place is approximately around $440 \mathrm{Tcf}^{14}$, out of which the U. S. Geological Survey estimates that approximately $50 \mathrm{Tcf}$ (trillion cubic feet) is extractable in these basins using current technology ${ }^{13}$. 


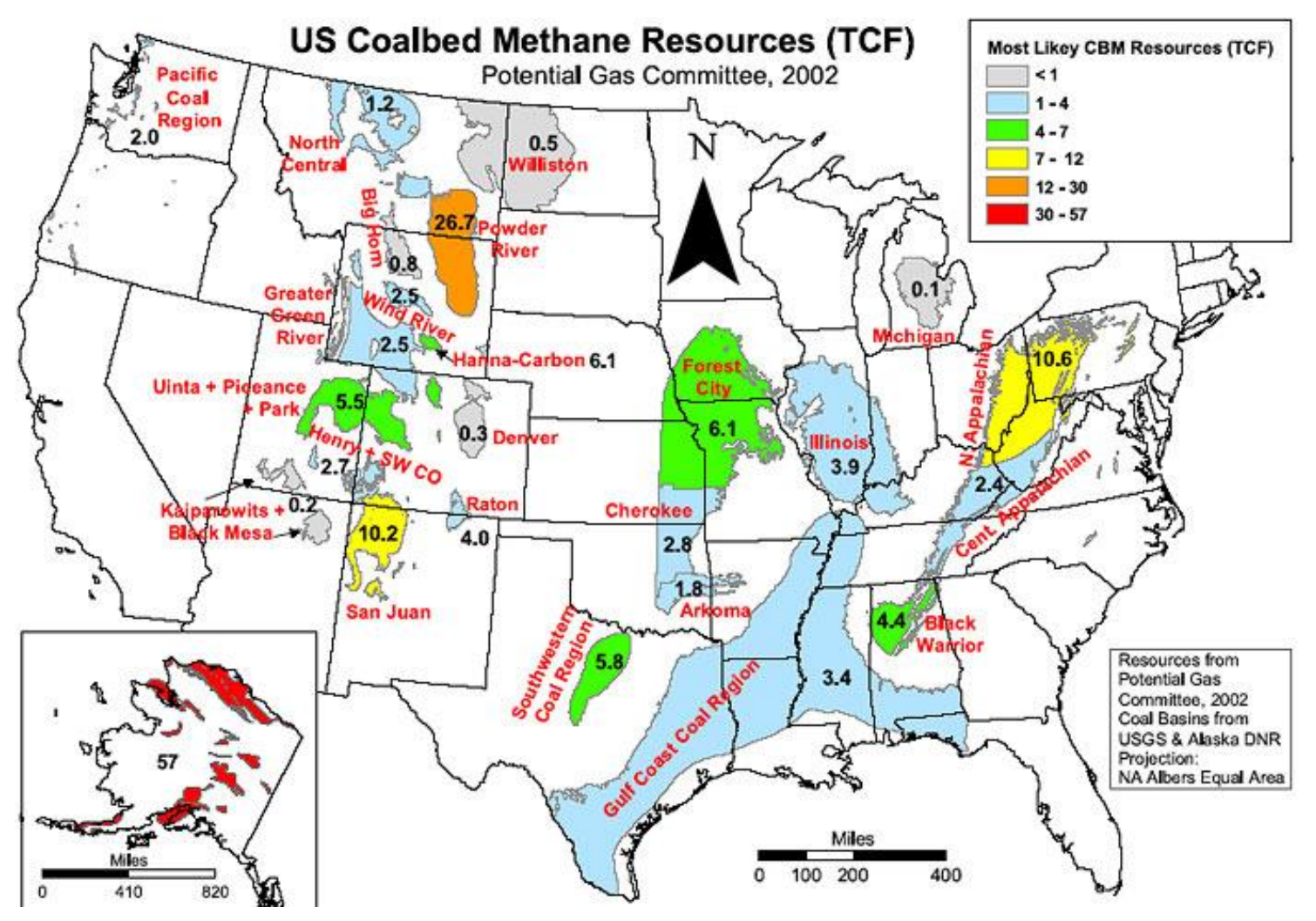

Figure 2.2. Major CBM basins in the USA

\subsubsection{A ppalachian Basin}

Coalbed Methane development and production began in the Appalachian basin nearly 60 years ago. The extensive coal deposits of the Appalachian Basin range across Pennsylvania, West Virginia, Ohio, Kentucky, Maryland, Tennessee, Virginia and the Black Warrior Basin of Alabama.

Coalbed natural gas is heavily commercialized in Virginia and Alabama and moderately developed in Pennsylvania, West Virginia and Kentucky. Reserve estimates for the Appalachian Basin range from $60 \mathrm{Tcf}$ to $76 \mathrm{Tcf}^{16}$.

In the southern part of the Appalachian Basin, CBM production has reached mature proportions. In Alabama's Black Warrior Basin, more than $100 \mathrm{Bcf}$ per year is produced from approximately 2,900 CBM wells penetrating coals of Pennsylvanian age. About 1,000 CBM wells in Virginia produce about $40 \mathrm{Bcf}$ per year ${ }^{15}$. 
In the northern Appalachian Basin, however, CBM activity has been much more diffuse. Some CBM production has been established in northern West Virginia and Pennsylvania and these areas are considered to have high potential, but the potential for CBM in eastern Kentucky and southern Ohio remains essentially untested.

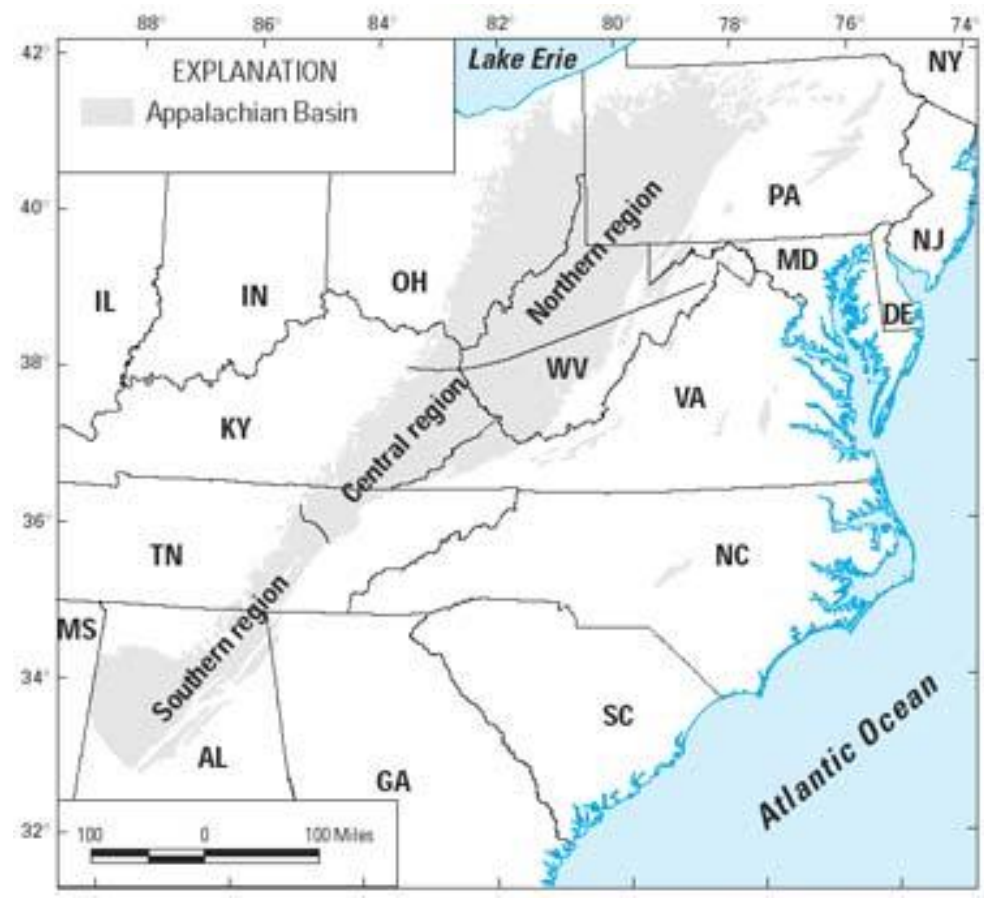

Figure 2.3. A ppalachian basin

\subsubsection{G as storage in coal reservoirs}

Coal seams are characterized by two distinct porosity systems: a uniformly distributed network of natural factures known as ,cleats $\square$ and matrix blocks containing a highly heterogeneous porous structure between these cleats. The cleat system is further divided into 2 types namely the face cleat and the butt cleat. (Figure 2.4) 


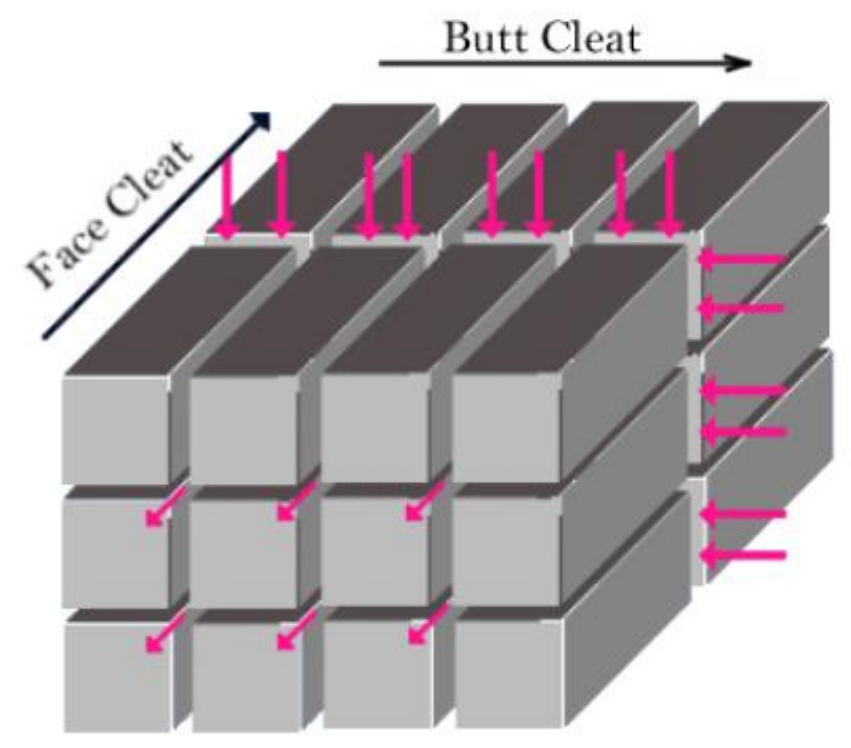

Figure 2.4. Cleat system in coal

Unlike conventional reservoirs, the gas in coal seams is mainly stored as sorbed gas on the internal surface of the micro porous coal. The surface area of coal in which methane is absorbed is very large and if the reservoir is saturated it can store up to 5 times the amount of gas stored in a conventional gas reservoir ${ }^{17}$.

\subsubsection{Production behavior in CBM reservoirs}

CBM reservoirs differ from conventional reservoirs in several aspects. Unlike conventional gas reservoirs, coal is both the reservoir rock and the source rock for methane ${ }^{9}$. CBM reservoirs are characterized by dual porosity systems: macropores and micropores. The macropores also known as cleats constitute the natural fractures common to all coal seams. Micropores, or the matrix, contain the vast majority of the gas. 


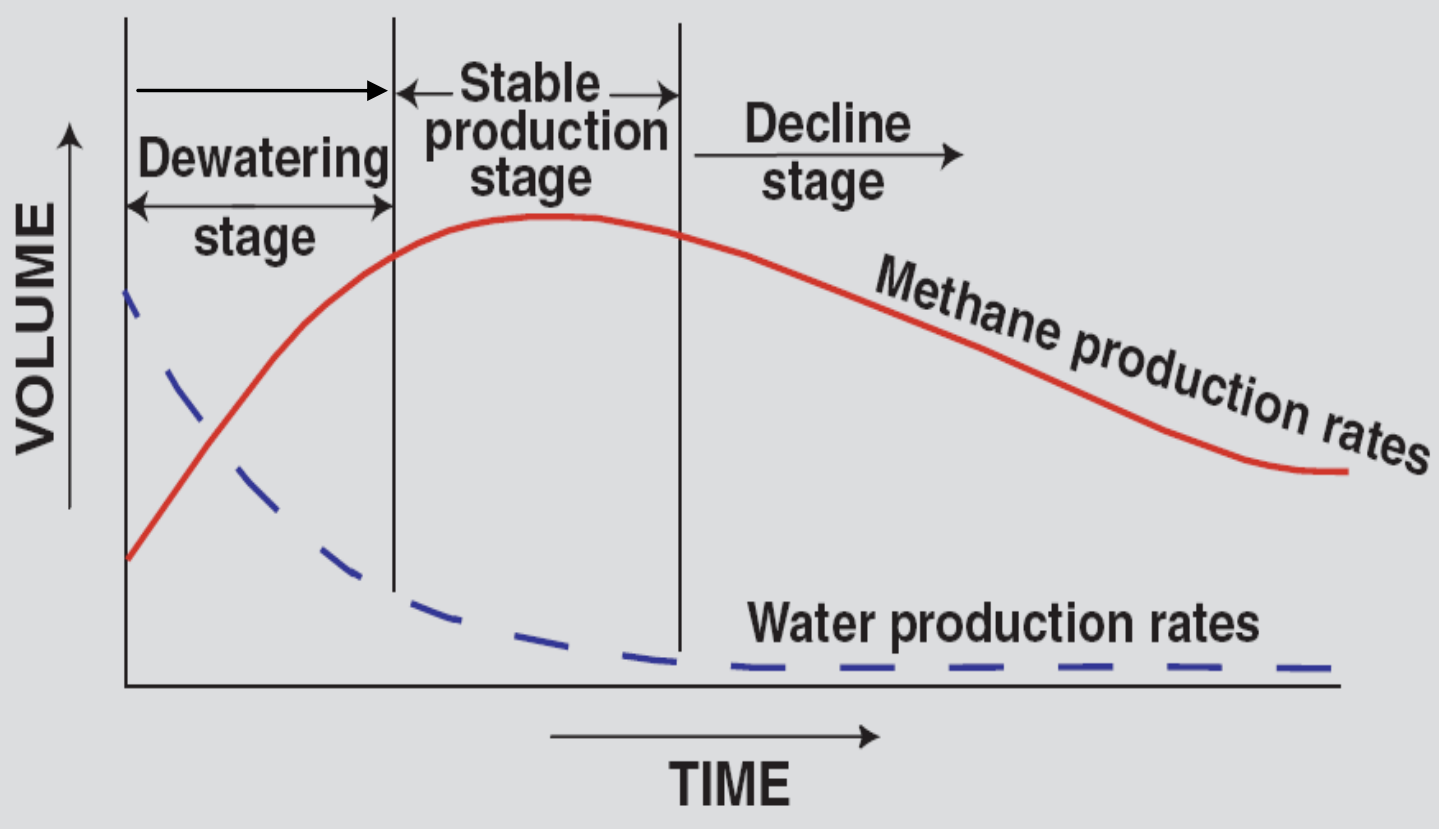

Figure 2.5. Production curve for a coal bed methane reservoir.

The production can be divided in three stages that are shown in Figure 2.5. During stage I, the cleats are usually filled with water. In order for gas to be released from the coal, its partial pressure must be reduced, and this is accomplished by removing water from the coalbed $^{10}$. Ideally, water production will relieve the hydraulic pressure on the coal in order to start the production by desorption of the gas from the coal. This process is known as Dewatering. The number of days of this dewatering process and the amount of produced water can vary widely. The gas is produced at very low rates during this phase. In stage II, the gas production rate increases until it reaches the maximum value, which is called peak gas rate. During this phase, the water production rate begins to decline as the coal is dewatered. The gas production is very stable during this stage and as such is referred to as ,stable production stagel. The dewatering period for coals can take from weeks to years.

During phase III, the conditions are stable. A typical decline trend defines the behavior of the gas production. During this phase, water production is low or insignificant. The water 
and gas relative permeability $\llbracket$ s do not change extensively. The pseudo-steady state exists for the rest of producing life.

\subsubsection{Coalbed M ethane Production Type C urves}

CBM reservoirs behavior were studied in depth and a set of type curves were developed as an efficient and economical tool to analyze and forecast the performance of CBM reservoirs by Garcia Anangela ${ }^{18}$ in 2004 as a part of her MS thesis (Figure 2.5) . During the study the Northern Appalachian Basin CBM reservoir characteristics were used as input to a reservoir simulator to predict the production behavior. A two dimensional, twophase Cartesian CBM model was built. The Cartesian model grid size was 13 x 13 blocks, each block with a length of $100 \mathrm{ft}$ for a total of 40 acres of spacing area. The reservoir simulation software used was GEM, developed by Computer Modeling group $(\mathrm{CMG})$. The software features a range of dual porosity and dual permeability techniques for modeling fractured formations. It also includes options for gas sorption in the matrix, gas diffusion through the matrix, and two phase flow through the fracture system.

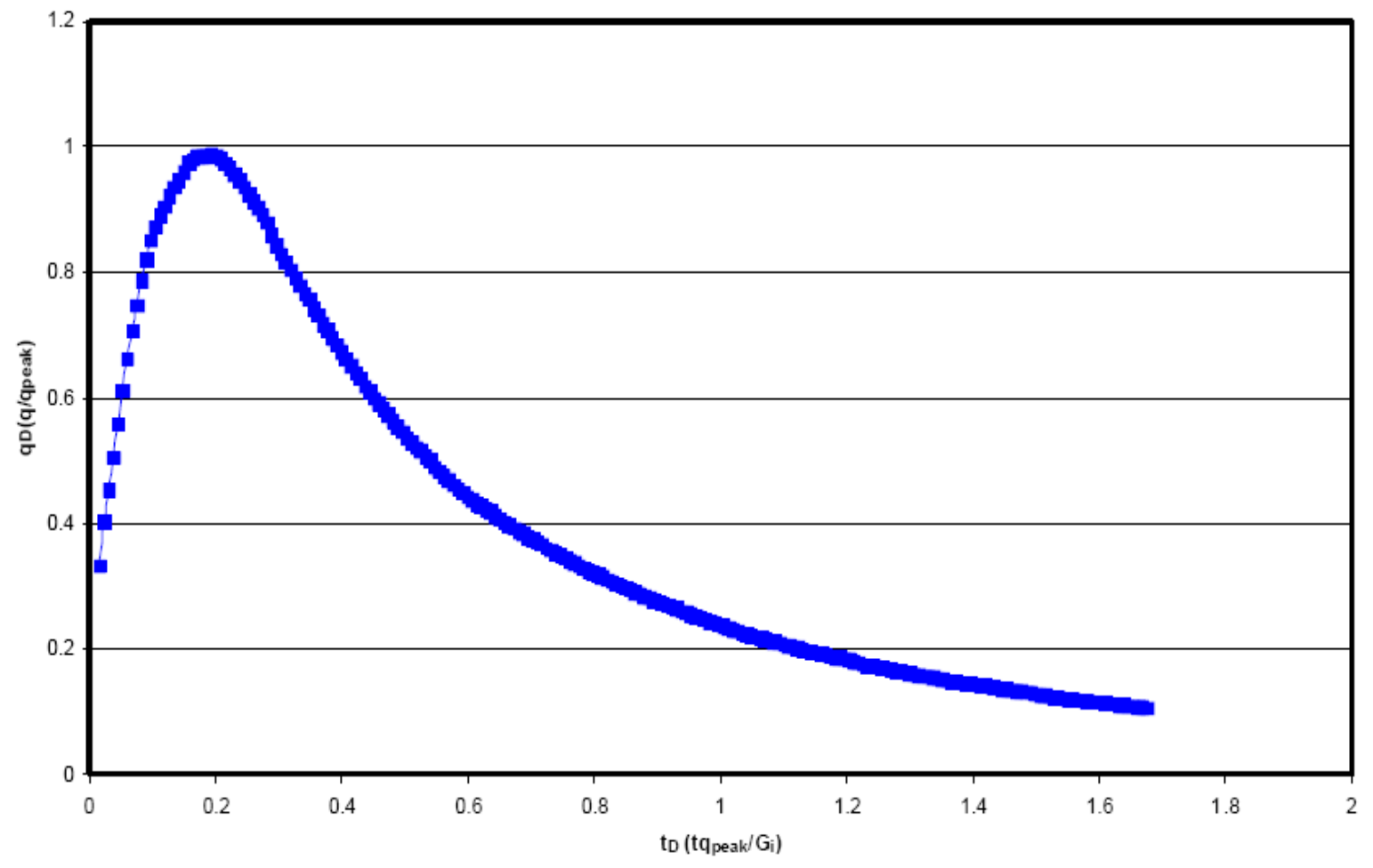

Figure 2.6. Production type curve (A dopted from G arcia, 2004) $)^{18}$ 
In order to develop a unique type curve, two dimensionless groups were introduced. The dimensionless gas rate and dimensionless time were presented as follows:

$$
\begin{aligned}
& t_{D} \frac{t q_{\text {peak }}}{G_{i}} \\
& q_{D} \frac{q}{q_{\text {peak }}}
\end{aligned}
$$

These definitions are based on those originally used for gas production decline type curve (Aminian et al 1990). In the equations, $\left(q_{\text {peak }}\right)_{g}$ represents the peak gas rate, $G_{i}$ is the initial gas in place. $G_{i}$ is calculated from the equation (3)

$$
G_{i} \quad 43560 A h G C
$$

, where $\mathrm{GC}$ is the gas content of coal in SCF/ton, and is the coal bulk density.

Garcia evaluated the dimensionless groups by varying eight different parameters. Garcia concluded that fracture pressure, sorption time, cleat porosity, and critical desorption pressure do not have any significant impact on CBM type curves whereas, flowing bottom-hole pressure appeared to be one of the properties with highest impact on CBM type curves particularly in the latter parts of production history.

The impact of stimulation was considered in a separate study by Sanchez ${ }^{19}$ and he concluded that skin factor does not influence the shape of the CBM gas type curve , however when the well is stimulated the skin factor alters the gas peak value that is used in development of dimensionless groups. Figure 2.7 shows the effect of skin factor on the type curves.

Arrey ${ }^{20}$ evaluated the impact of Langmuir isotherm constants, Langmuir Pressure $\left(\mathrm{P}_{\mathrm{L}}\right)$ and Langmuir Volume $\left(\mathrm{V}_{\mathrm{L}}\right)$ on the gas production type curves. Arrey concluded that changes in $\mathrm{V}_{\mathrm{L}}$ values do not significantly impact the shape of the gas production type curves however; changes in $\mathrm{P}_{\mathrm{L}}$ values have a significant impact on the gas production 
type curves. Figure 2.8 shows the effect of $\mathrm{P}_{\mathrm{L}}$ changes on the $\mathrm{CBM}$ gas production type curves.

Bhavsar $^{21}$ in 2005 developed a unique set of water production type curves as a part of his MS thesis. The effects of 9 formation and operational parameters on the type curves were studied. It was concluded that flowing pressure, critical desorption pressure and skin factor were found to influence the water production type curves.

He also defined and verified two set of dimensionless rate and time were defined for water. The water dimensionless rate and time were defined as:

$$
\begin{gathered}
q_{w D} \frac{q_{w}}{q_{i w}} \\
t_{w D} \frac{t * q_{i w}}{w_{i}}
\end{gathered}
$$

In the above equations, $q_{i w}$ represents the initial (maximum) water rate and $W_{i}$ is the initial water in the cleat system which can be calculated by the following equation:

$$
\text { Wi 43560Ah }{ }_{f} S_{w i}
$$

Where, $A$ is the reservoir area in acres, $h$ is the thickness of coal in $\mathrm{ft}$, is the cleat system porosity and $\mathrm{S}_{\mathrm{wi}}$ is the initial cleat system water saturation. 


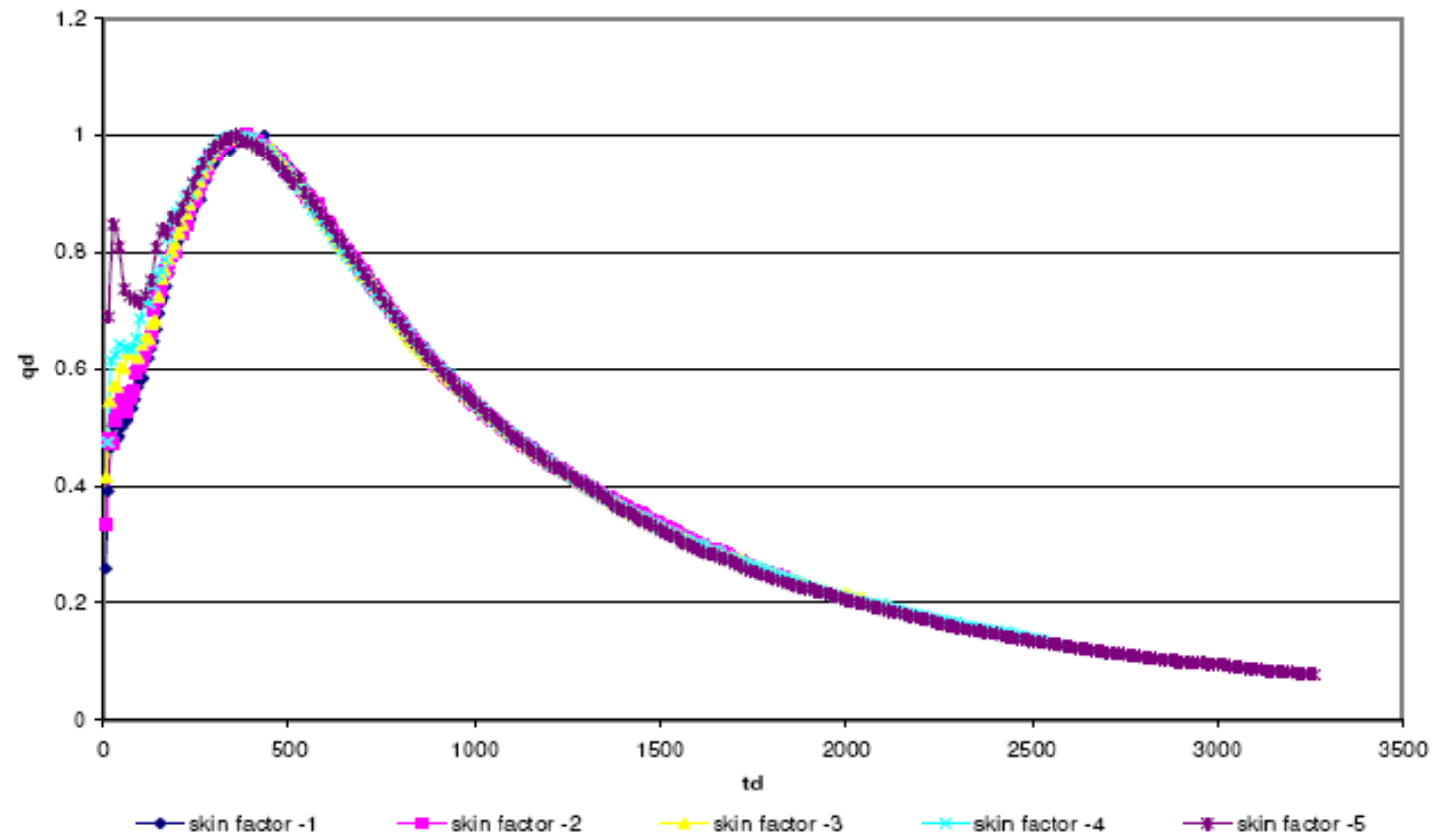

Figure 2.7. E ffect of skin factor on the C BM production type curve ${ }^{19}$

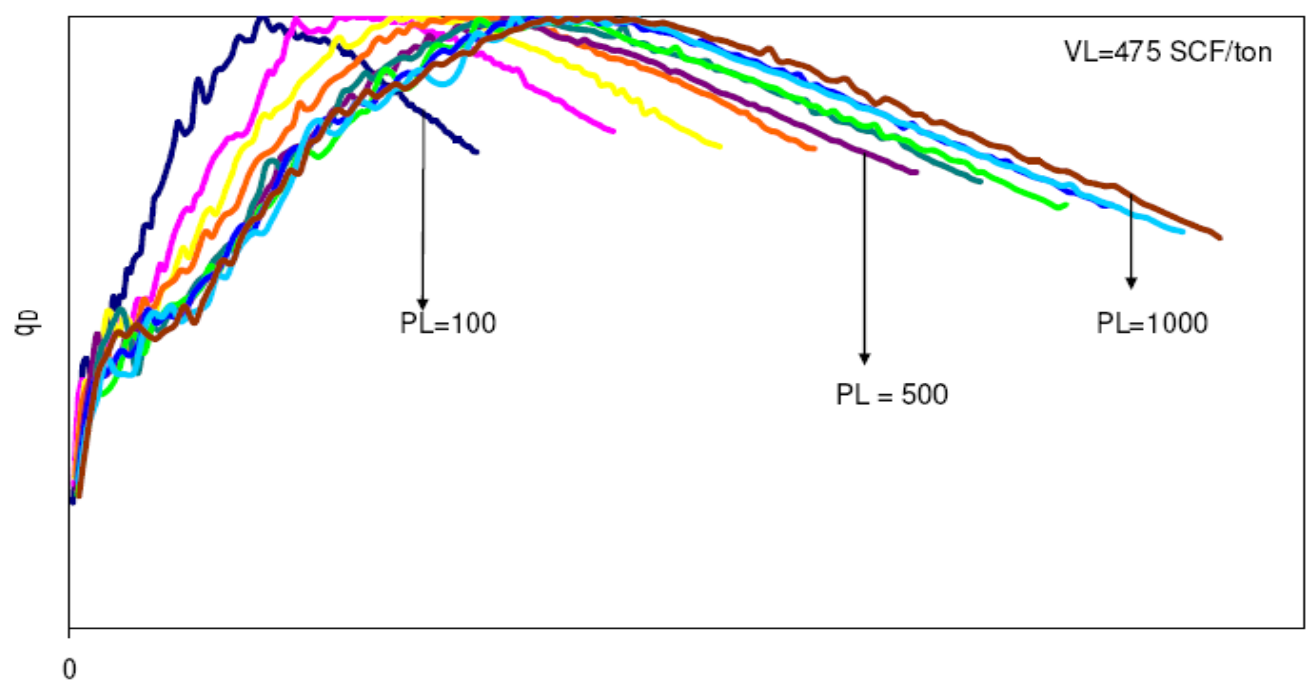

$t_{D}$

Figure 2.8. E ffect of $L$ angmuir Pressure $\left(P_{L}\right)$ on the $C B M$ production type curve $e^{20}$ 


\subsubsection{R elative Permeabilty}

The relative permeability values for coal bed methane reservoirs are difficult to obtain. They cannot be accurately measured in the laboratory due to difficulties in obtaining a representative coal sample from the reservoir. The only practical method to obtain the realistic values of relative permeability values is by history matching the production history ${ }^{23}$.

The effect of relative permeability on the type curves for Coalbed methane reservoirs has been studied in detail during the course of this research. Absolute permeability and relative permeability are two of the most important natural fracture system flow properties that affect gas and water production rates. Absolute permeability is a property of the porous medium and is a measure of the capacity of the medium to transmit fluids. When two or more fluids flow at the same time, the relative permeability of each phase at a specific saturation is the ratio of the effective permeability of the phase to the absolute permeability $^{24}$, or:

$$
\begin{aligned}
& \mathrm{k}_{\mathrm{ro}}=\frac{\mathrm{k}_{\mathrm{o}}}{\mathrm{k}} \\
& \mathrm{k}_{\mathrm{rg}}=\frac{\mathrm{k}_{\mathrm{g}}}{\mathrm{k}} \\
& \mathrm{k}_{\mathrm{rw}}=\frac{\mathrm{k}_{\mathrm{w}}}{\mathrm{k}}
\end{aligned}
$$

Where,

$\mathrm{k}_{\mathrm{ro}}=$ relative permeability to oil

$\mathrm{k}_{\mathrm{rg}}=$ relative permeability to gas

$\mathrm{k}_{\mathrm{rw}}=$ relative permeability to water

$\mathrm{k}=$ absolute permeability

$\mathrm{k}_{\mathrm{o}}=$ effective permeability to oil for a given oil saturation

$\mathrm{k}_{\mathrm{g}}=$ effective permeability to gas for a given gas saturation

$\mathrm{k}_{\mathrm{w}}=$ effective permeability to water at some given water 
The values of relative permeability in coal bed methane reservoirs primarily depends upon 3 constants, which are $\mathrm{n} \square, \mathrm{m} \square$ and K. 4 different coal samples have been considered to obtain relative permeability data. Using the relative permeability values of these 4 samples and the equations for $\mathrm{k}_{\mathrm{rg}}$ and $\mathrm{k}_{\mathrm{rw}}$ that are stated in section 3.2, the ranges for all the 3 constants were obtained. The ranges for the relative permeability are shown in Table 3.3

\subsubsection{GE M}

Reservoir models are excellent tools to study the impact of reservoir properties on production and organize data for a particular prospect.

Computer modeling group (CMG) is one engineering computer program capable of simulating oil and gas reservoirs. The computer program is used to characterize reservoirs where the importance of the fluids composition and their interactions are essential to understand and maximize the recovery process. CMG is based on six different applications shown in Figure 2.6.

(a) BUILDER, Pre-processing Applications

(b) IMEX, Black Oil Simulator

(c) STARS, Steam Thermal Advanced Processes

(d) GEM, Generalized Equation-of-State Model Compositional Reservoir Simulator

(e) WINPROP, Phase Behavior Analysis

(f) RESULTS, Post-processing applications.

During the study there were only three applications used for our studies. These applications used were BUILDER, GEM, and RESULTS.

BUILDER is an application used to prepare reservoir simulation models. It makes the design and provides a Windows interface which organizes data in an easy way.

BUILDER presents two modules depending on the objectives which are: (a) GridBuilder and (b) ModelBuilder. 
The GridBuilder is used to create simulation grids and rock property data for GEM and other applications. It allows the user to easily create, edit, and positioning grids with respect to geological maps, interpolating geological structure, and rock properties. The grid is displayed in 2D and 3D views to allow the user to check the grid performance.

The ModelBuilder helps the user prepare input data files for GEM and other applications. It displays Relative Permeability and PVT curves in graphic from which it can be adjusted directly. In addition, the ModelBuilder has an automatic error checking and data validation.

GEM is an essential engineering tool for modeling any type of reservoir with complicated phase behavior interaction where the importance of the fluid composition and their interactions are essential to the understanding of the recovery process. GEM is a highly optimized simulator that has been proven in numerous field production situations around the world.

RESULTS is GEM $\llbracket s$ set of post processing applications, designed for visualizing and reporting simulator output. With RESULTS, users are able to analyze the output, prepare 2D and 3D plots, generate several informative graphs, and prepare tables of required information to be included in a report. Visualization capabilities offered by RESULTS make simulation $\llbracket s$ output easier to understand and provide new insight to analyze recovery process. RESULTS is composed of two modules: (a) Results Graph and (b) Results Report.

Results Graph, produce high quality 3D graphs of well production and injection data from the simulator runs. Data can be displayed for individual wells or well layers, for group of wells or reservoir sectors. It is a great tool to understand the recovery process of the reservoir and to interpret the production of data of a specific well. Results Report produces tabular reports of any type of data generated during the reservoir simulation including well data and reservoir grid properties. It can also be used to compare data from different runs and generate economic analysis for discussion 
For our research study, we used, ModelBuilder and GridBuilder to build the 2D Cartesian model. GEM was used to run the simulated model. The outputs of the runs were analyzed in RESULTS and 2D plots were developed in Results Graph.

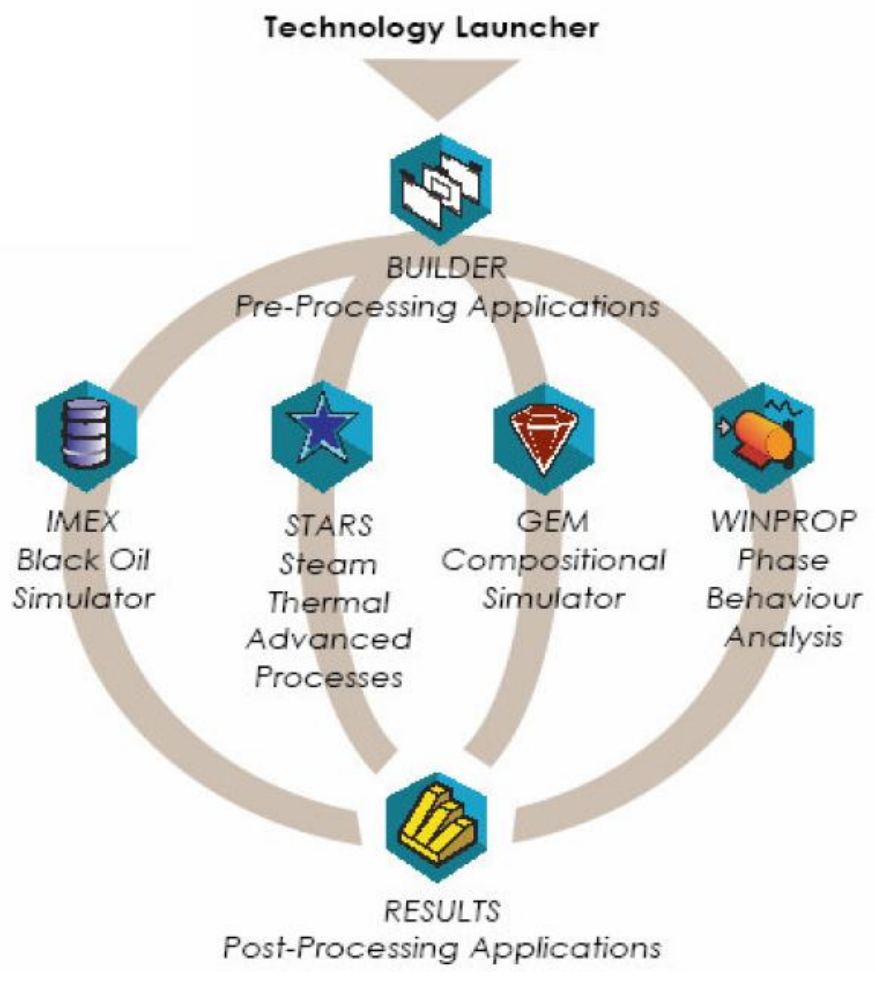

Figure 2.6. CM G Model 


\section{OBJECTIVE AND METHODOLOGY}

The prime motive of this research was to study the impact of relative permeability on the production behavior of CBM reservoirs. Also, one of the objectives of this study were to develop a correlation for the peak gas production rate $\left(q_{\text {peak }}\right)_{g}$ and the constants (n\, $m \square$ and $\mathrm{K}$ ) governing the relative permeability

In order to achieve the objectives, a methodology consisting of the following steps was used:

1. Development of a base model for coalbed methane production in Northern Appalachian Basin.

2. To evaluate the impact of relative permeability on the production type curves of a typical coal bed methane reservoir.

3. To develop a correlation for the peak production rate for gas and the constants governing the relative permeability ( $\mathrm{n} \square, \mathrm{m} \square$ and $\mathrm{K}$ )

4. To verify the accuracy of the type curve and the correlation.

Each of the 4 steps will be discussed below.

\subsection{Development of a base model for C oalbed methane production in Northern A ppalachian basin}

A two-dimensional Cartesian (CBM base) model was developed for an under-saturated CBM reservoir with a well located at the center of the drainage area. 


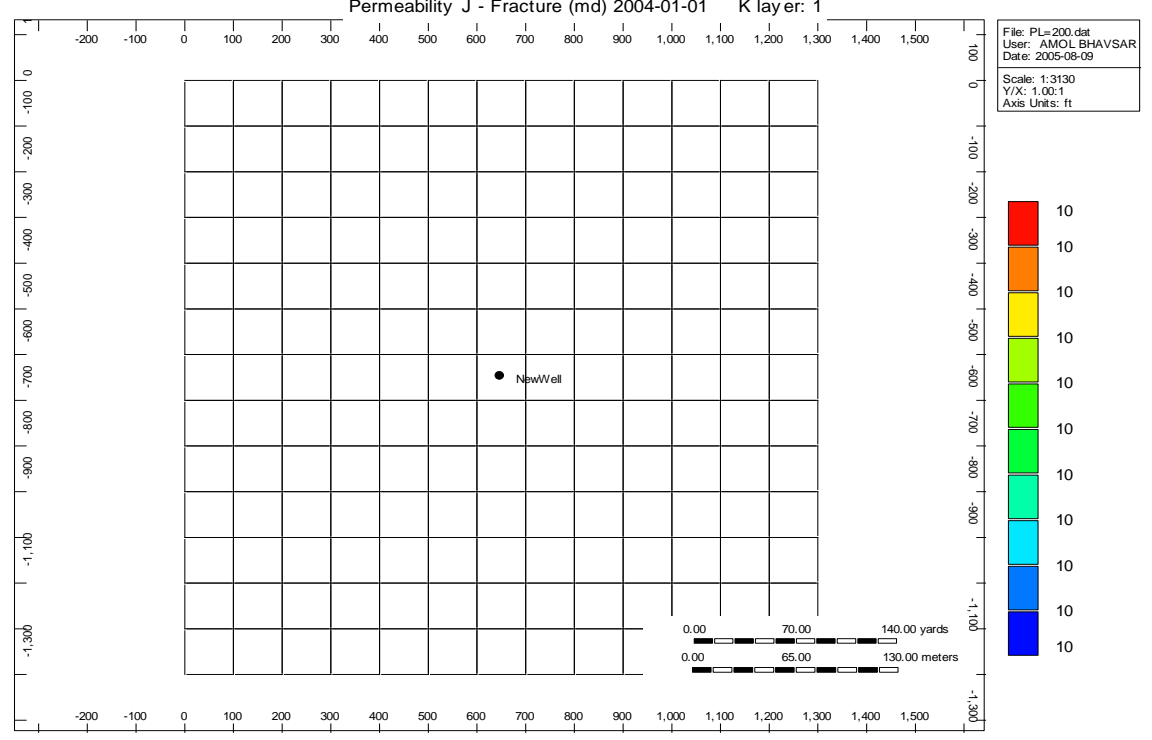

Figure 3.1. 2-D view of the reservoir model being used

The reservoir simulation software used in this study was GEM developed by the Computer Modeling Group (CMG) ${ }^{22}$. The reservoir parameters used to develop the base model are summarized in Table 3.1. The simulation runs were made by varying several of the key parameters over the ranges provided in Table 3.1.

Table 3.1.R eservoir parameters used to develop the base model

\begin{tabular}{|c|c|}
\hline PARAMETERS & BASE MODEL VALUE \\
\hline Model & Dual Porosity \\
\hline Shape Factor Formulation & Gilman-Kazemi \\
\hline Matrix- Fracture Transfer Model & $\begin{array}{c}\text { Pseudo-capillary Pressure with } \\
\text { Correction }\end{array}$ \\
\hline Model Geometry & 2D-Cartesian \\
\hline Grid Size & $100 \mathrm{ft} \times 100 \mathrm{ft}$ \\
\hline Reservoir Area & $40 \mathrm{acres}$ \\
\hline Thickness & $10 \mathrm{ft}$ \\
\hline Matrix Porosity & $0.5 \%$ \\
\hline Fracture Porosity & $2 \%$ \\
\hline Matrix Water Saturation & $0.5 \%$ \\
\hline Initial Fracture Water Saturation & $100 \%$ \\
\hline Matrix Permeability & $0.01 \mathrm{md}$ \\
\hline Fracture Permeability & $10 \mathrm{md}$ \\
\hline Fracture Spacing & $0.2 \mathrm{ft}$ \\
\hline Initial Pressure & $600 \mathrm{psia}$ \\
\hline Temperature & $113 \mathrm{O} \mathrm{F}$ \\
\hline Langmuir Pressure $\left(\mathrm{P}_{\mathrm{L}}\right)$ & $167.6 \mathrm{psia}$ \\
\hline Langmuir Volume $\left(\mathrm{V}_{\mathrm{L}}\right)$ & $233.8 \mathrm{SCF} / \mathrm{ton}$ \\
\hline Coal Sorption Time & $35 \mathrm{days}$ \\
\hline Critical Desorption Pressure & $300 \mathrm{psia}$ \\
\hline Rock Density & $89.63 \mathrm{lb} / \mathrm{ft}^{3}$ \\
\hline Skin Factor & 0 \\
\hline Bottom Hole Pressure (constant) & $50 \mathrm{psia}$ \\
\hline
\end{tabular}




\subsection{E valuating the impact of relative permeability on the production type curves}

The relative permeability characteristics have significant impact on the gas and water production due to the two-phase flow condition at the early stages of production ${ }^{23}$. The set of equations that characterize CBM relative permeability are considered here. The equations are provided below:

$$
\begin{array}{ccc}
k_{\mathrm{rg}} & \mathrm{K}\left(1 \quad \mathrm{Sw}^{*}\right)^{\mathrm{m}^{\prime}} & (4)^{23} \\
\mathrm{k}_{\mathrm{rw}} & \left(\mathrm{SW}^{*}\right)^{n^{\prime}} & (5)^{23}
\end{array}
$$

To evaluate the effect of various values of relative permeability on the type curves, the constants $\mathrm{n} \square, \mathrm{m} \square$ and $\mathrm{K}$ were varied over different ranges.

To obtain the ranges of $\mathrm{n} \square, \mathrm{m} \square$ and $\mathrm{K}$, the relative permeability values of 4 different coal samples were considered. The samples are:

\section{Rock Creek}

Pittsburgh

CMG Model

Calculated value

By using the $\mathrm{k}_{\mathrm{rg}}$ and $\mathrm{k}_{\mathrm{rw}}$ values of the samples aforementioned, we substitute them in equations (4) and (5) to get values of $\mathrm{n} \square, \mathrm{m} \square$ and $\mathrm{K}$ in each case. The values for each case are shown in Table 3.2.

Table 3.2. Values of $n^{\prime}, \mathbf{m}^{\prime}$ and $K$ from each sample

\begin{tabular}{|c|c|c|c|c|}
\hline & Calculated & Model & Rock creek & Pittsburgh Coal \\
\hline $\mathbf{n}^{\prime}$ & 1.5 & 3.779 & 5.999 & 1.889 \\
\hline $\mathbf{m}^{\prime}$ & 3 & 2.1 & 1.93 & 1 \\
\hline $\mathbf{K}$ & 0.9 & 0.71 & 0.83 & 0.95 \\
\hline
\end{tabular}


Thus, we get the ranges of all of the constants. The ranges obtained are shown in Table 3.3 .

Table 3.3. $R$ anges of $n^{\prime}, m^{\prime}$ and $K$ used in this study

\begin{tabular}{|c|c|c|}
\hline Constant & Base M odel & Range used in this study \\
\hline $\mathrm{n}^{\prime}$ & 3.8 & $1.5-6$ \\
\hline $\mathrm{m}^{\prime}$ & 2.1 & $1-3$ \\
\hline $\mathrm{K}$ & 0.7 & $0.7-1.0$ \\
\hline
\end{tabular}

\subsection{Developing a correlation for the peak production rate for gas and the constants governing therelative permebility ( $n^{\prime}, \mathrm{m}^{\prime}$ and $K$ )}

In the section above we have seen that type curves can be used as a simple and quick tool to predict gas and water rates for evaluation of a prospect. To do this, it is necessary to estimate $\left(q_{\text {peak }}\right)_{g}$ and $G_{i}$ for gas production predictions from available formation properties. Equations can be used for calculation of $G_{i}$ for gas. However, estimation of $\left(q_{\text {peak }}\right)_{g}$ is complicated due to two-phase flow conditions. To overcome this problem, the variation of $\left(q_{\text {peak }}\right)_{g}$ with various parameters was investigated to develop a correlation.

The following equation defines the dimensionless peak gas rate.

$$
q_{\text {peak d }} \frac{1422 T E z}{K h\left(P_{\text {matrix }}{ }^{2} P_{\text {wf }}{ }^{2}\right)} q_{\text {peak }} \ldots . . .
$$

In order to develop a correlation between $\left(q_{p e a k}\right)_{\mathrm{d}}$ and relative permeabilty, the following steps were considered:

1. A series of runs with simulator were conducted by changing the constants $\mathrm{n} \square, \mathrm{m} \square$ and $\mathrm{K}$.

2. The simulator output was used to determine qpeak for each case.

3. qpeak values were converted to (qpeak $)_{\mathrm{d}}$ using Equation 6. 
4. The values of (qpeak $)_{d}$ were plotted against $\mathrm{n} \square, \mathrm{m} \square$ and $\mathrm{K}$.

The plots of $\mathrm{n} \square, \mathrm{m} \square$ and $\mathrm{K}$ are shown in figures $4.11,4.12$ and 4.13 respectively.

A linear multiple regression analysis was performed to develop the correlation. To achieve the best fit, the constants $\mathrm{n} \square, \mathrm{m} \square$ and $\mathrm{K}$ were correlated with a $\mathrm{R}^{2}$ value of 0.95 .

Table 3.4. L inear multiple regression analysis

\begin{tabular}{|l|l|l|l|l|}
\hline & $\mathbf{K}$ & $\mathbf{m}^{\prime}$ & $\mathbf{n}^{\prime}$ & Constant \\
\hline Co-efficient values & $\mathbf{9 8 . 3 9 7 6 1}$ & -41.394 & -9.81021 & $\mathbf{1 3 9 . 6 7 3 2}$ \\
\hline $\begin{array}{l}\text { Standard error values for coefficients } \mathbf{K}, \mathbf{m}^{\prime} \text { and } \\
\mathbf{n}^{\prime}\end{array}$ & 18.52135 & 2.12126 & 1.274646 & 16.83292 \\
\hline $\mathbf{R}^{\mathbf{2}}$ & $\mathbf{0 . 9 5 2 8 7 8}$ & & & \\
\hline
\end{tabular}

From the obtained results, following is the correlation for peak production rate for gas.

$$
\left(q_{\text {peak }}\right)_{g d} \quad 9.81021^{k} n^{\prime} \quad 41.394 * m^{\prime} \quad 98.39^{*} \mathrm{~K} \quad 139.67
$$

\subsection{Verification of the type curves to forecast gas production}

The last stage consisted on validating the accuracy of the production type curve without having any production data available. The correlation which is a function of the the constants $\mathrm{n} \square, \mathrm{m} \square$ and $\mathrm{K}$ was used to estimate peak gas rate. Then, the estimated (qpeak) was compared with the simulated outputs to evaluate the uniqueness of the correlation. In order to complete this phase the following procedure was applied.

1. A new case was built to test the type curve. This case was simulated using different reservoir parameters from the ones used during the development of the correlation for (qpeak) prediction.

2. Peak gas rate was estimated using Equation (6) for the new case. In Equation (6), the $(\mathrm{qpeak})_{\mathrm{d}}$ was estimated using the correlation that had been developed. 
3. Using the (qpeak) we get the values for $\mathrm{q}$ and $\mathrm{t}$ from the dimensionless groups of the nearest match of the new case.

4. The time and flow rate of both the curves were plotted and the match was analyzed.

The match is shown in Figure 4.14. 


\section{CHAPTER 4}

\section{RESULTS AND DISCUSSION}

To evaluate the reliability of the gas production type curves and the correlation for $\left(q_{\text {peak }}\right)_{g_{D}}$ a set of the constants $\mathrm{n} \square, \mathrm{m} \square$ and $\mathrm{K}$ are considered. The values of constants used as inputs to $\mathrm{CBM}$ reservoir simulator were $\mathrm{n} \square=4, \mathrm{~m} \square=1, \mathrm{~K}=0.9$. The values were used to generate the production histories. These production histories were used for the purpose of type curve matching along with prediction of gas peak rate. A unique match was obtained with the type curves as shown in Figure 4.14. The effect of the different constants are analyzed and discussed in the sections below.

\subsection{E ffect of constant $K$}

From the results of the simulator runs using the different values of relative permeability computed by varying the constants $\mathrm{n} \square, \mathrm{m} \square$ and $\mathrm{K}$, we found that the impact of constant $\mathrm{K}$ was not very significant. The relative permeability values for different values of $\mathrm{K}$ are shown in tables 4.1, 4.2, 4.3 and 4.4. The relative permeability curves for different values of $\mathrm{K}$ are shown in figures 4.1, 4.2, 4.3 and 4.4. The effect of $\mathrm{K}$ on gas production is shown in the figures 4.5 and 4.6 below:

Table4.1. Relative permeability values for $K=0.7\left(n^{\prime}=1.5, m^{\prime}=1\right)$

\begin{tabular}{|r|r|r|r|}
\hline \multicolumn{1}{l|l}{ Sw* } & Sw & \multicolumn{1}{l|}{ Krw } & \multicolumn{1}{l|}{ Krg } \\
\hline 0 & 0 & 0 & 0.7 \\
\hline 0 & 0.1 & 0 & 0.7 \\
\hline 0.2222222 & 0.3 & 0.104757 & 0.544444 \\
\hline 0.4444444 & 0.5 & 0.296296 & 0.388889 \\
\hline 0.6666667 & 0.7 & 0.544331 & 0.233333 \\
\hline 0.8888889 & 0.9 & 0.838052 & 0.077778 \\
\hline 1 & 1 & 1 & 0 \\
\hline
\end{tabular}




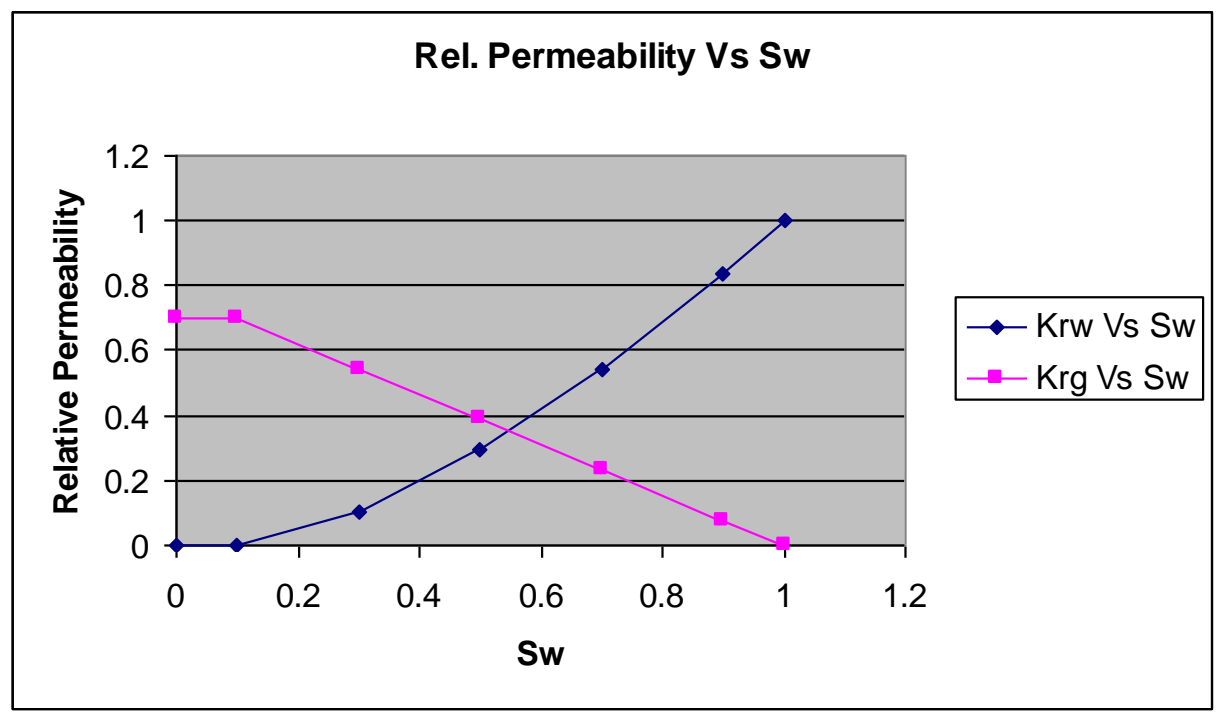

Figure 4.1. $R$ elative permeability curves for $K=0.7\left(n^{\prime}=1.5, m^{\prime}=1\right)$

Table 4.2. R elative permeability values for $K=0.8\left(n^{\prime}=1.5, m^{\prime}=1\right)$

\begin{tabular}{|r|r|r|r|}
\hline \multicolumn{1}{|l|}{ Sw* } & Sw & \multicolumn{1}{l|}{ Krw } & \multicolumn{1}{l|}{ Krg } \\
\hline 0 & 0 & 0 & 0.8 \\
\hline 0 & 0.1 & 0 & 0.8 \\
\hline 0.2222222 & 0.3 & 0.104757 & 0.622222 \\
\hline 0.4444444 & 0.5 & 0.296296 & 0.444444 \\
\hline 0.6666667 & 0.7 & 0.544331 & 0.266667 \\
\hline 0.8888889 & 0.9 & 0.838052 & 0.088889 \\
\hline 1 & 1 & 1 & 0 \\
\hline
\end{tabular}

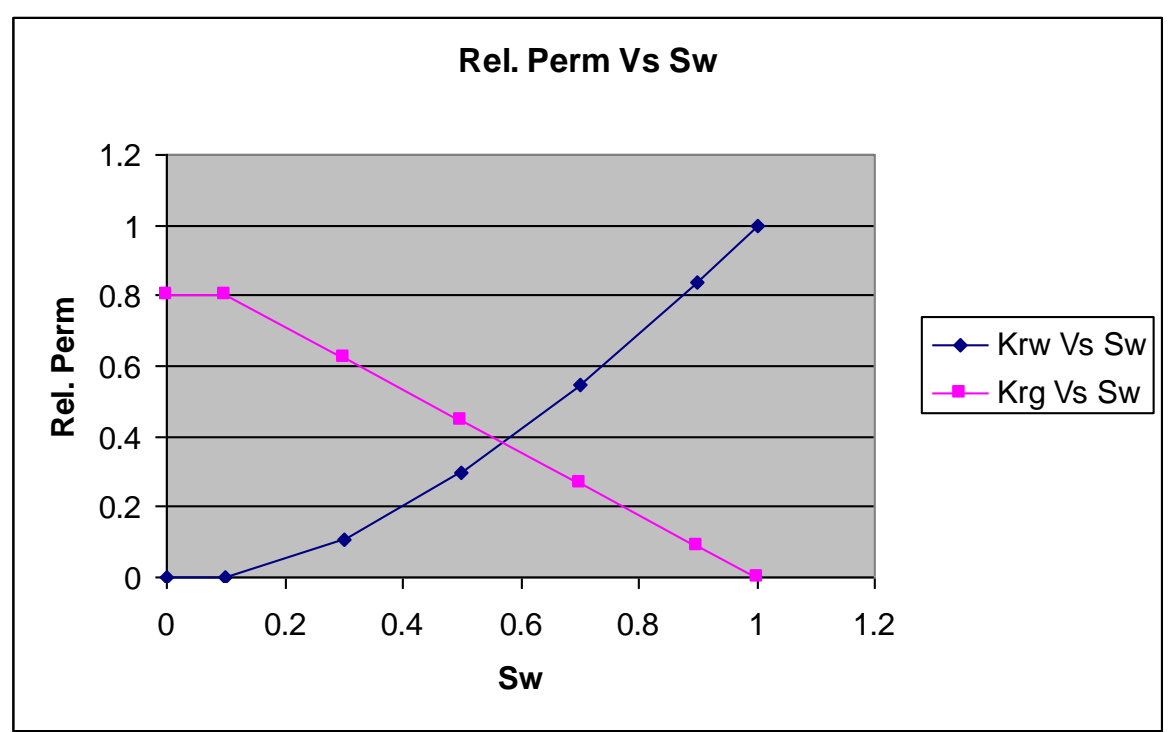

Figure 4.2. R elative permeability curves for $K=0.8\left(n^{\prime}=1.5, m^{\prime}=1\right)$ 
Table 4.3. R elative permeability values for $K=0.9\left(n^{\prime}=1.5, m^{\prime}=1\right)$

\begin{tabular}{|r|r|r|r|}
\hline \multicolumn{1}{|l|}{ Sw* } & Sw & \multicolumn{1}{l|}{ Krw } & \multicolumn{1}{l|}{ Krg } \\
\hline 0 & 0 & 0 & 0.9 \\
\hline 0 & 0.1 & 0 & 0.9 \\
\hline 0.2222222 & 0.3 & 0.104757 & 0.7 \\
\hline 0.4444444 & 0.5 & 0.296296 & 0.5 \\
\hline 0.6666667 & 0.7 & 0.544331 & 0.3 \\
\hline 0.8888889 & 0.9 & 0.838052 & 0.1 \\
\hline 1 & 1 & 1 & 0 \\
\hline
\end{tabular}

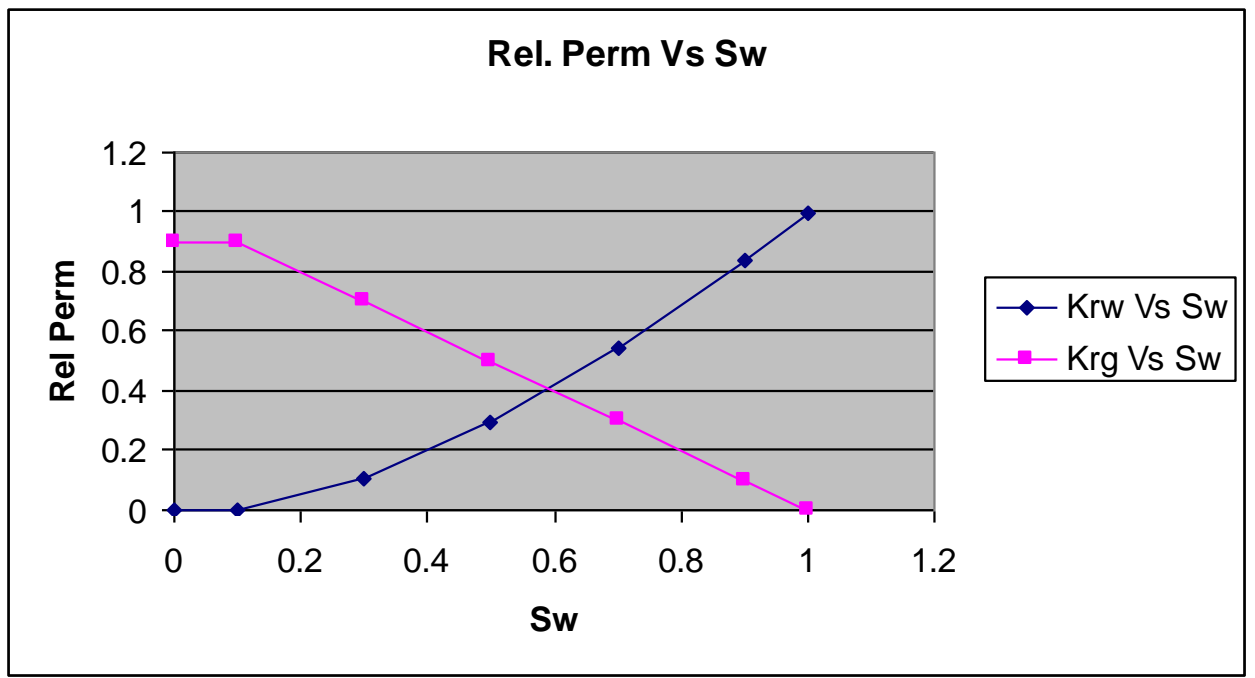

Figure 4.3. R elative permeability curves for $K=0.9\left(n^{\prime}=1.5, m^{\prime}=1\right)$

Table 4.4. R elative permeability values for $K=1\left(n^{\prime}=1.5, m^{\prime}=1\right)$

\begin{tabular}{|r|r|r|r|}
\hline \multicolumn{1}{|l|l|l|}{ Sw* } & \multicolumn{1}{l|}{ Krw } & \multicolumn{1}{l|}{ Krg } \\
\hline 0 & 0 & 0 & 1 \\
\hline 0 & 0.1 & 0 & 1 \\
\hline 0.2222222 & 0.3 & 0.104757 & 0.777778 \\
\hline 0.4444444 & 0.5 & 0.296296 & 0.555556 \\
\hline 0.6666667 & 0.7 & 0.544331 & 0.333333 \\
\hline 0.8888889 & 0.9 & 0.838052 & 0.111111 \\
\hline 1 & 1 & 1 & 0 \\
\hline
\end{tabular}




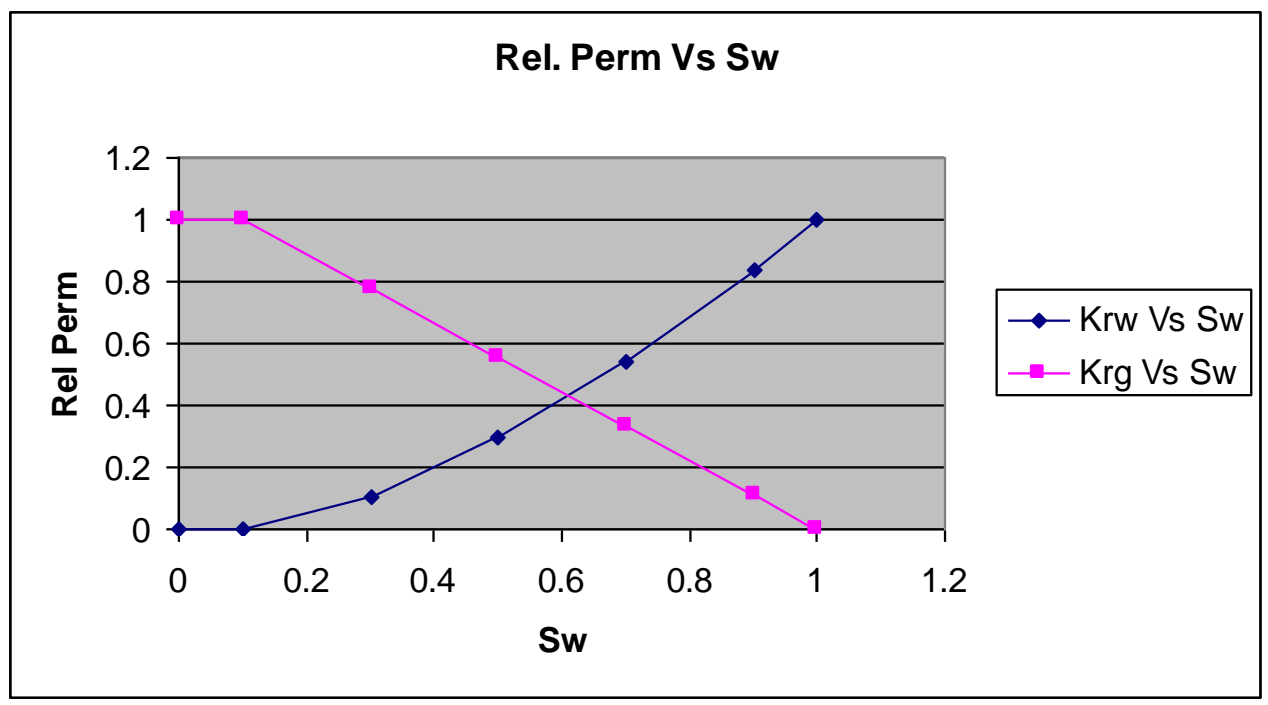

Figure 4.4. R elative permeability curves for $K=1\left(n^{\prime}=1.5, m^{\prime}=1\right)$

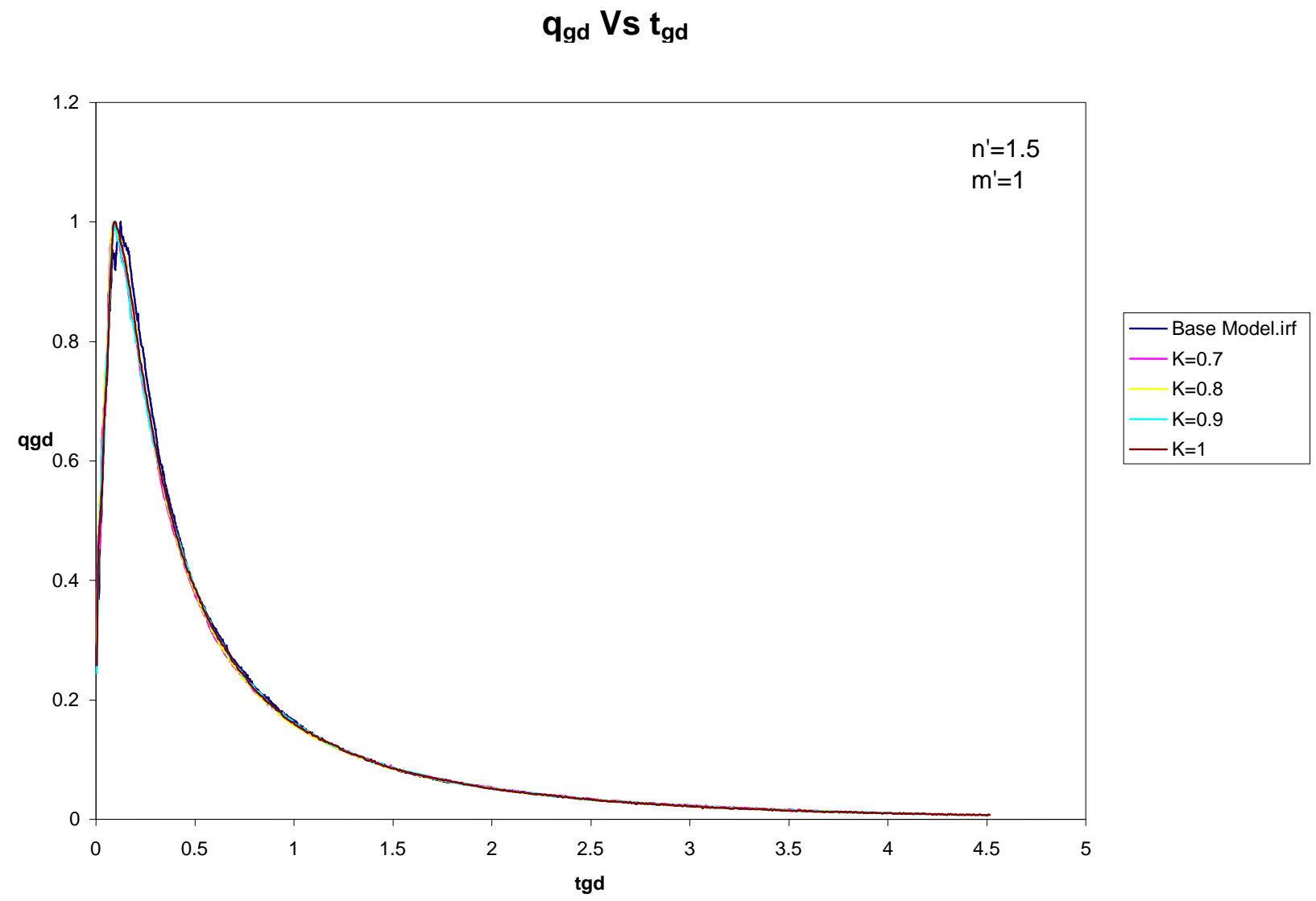

Figure 4.5. $C$ artesian curve of $q_{g d}$ versus $t_{g d}$ to study the effect of $K$ 


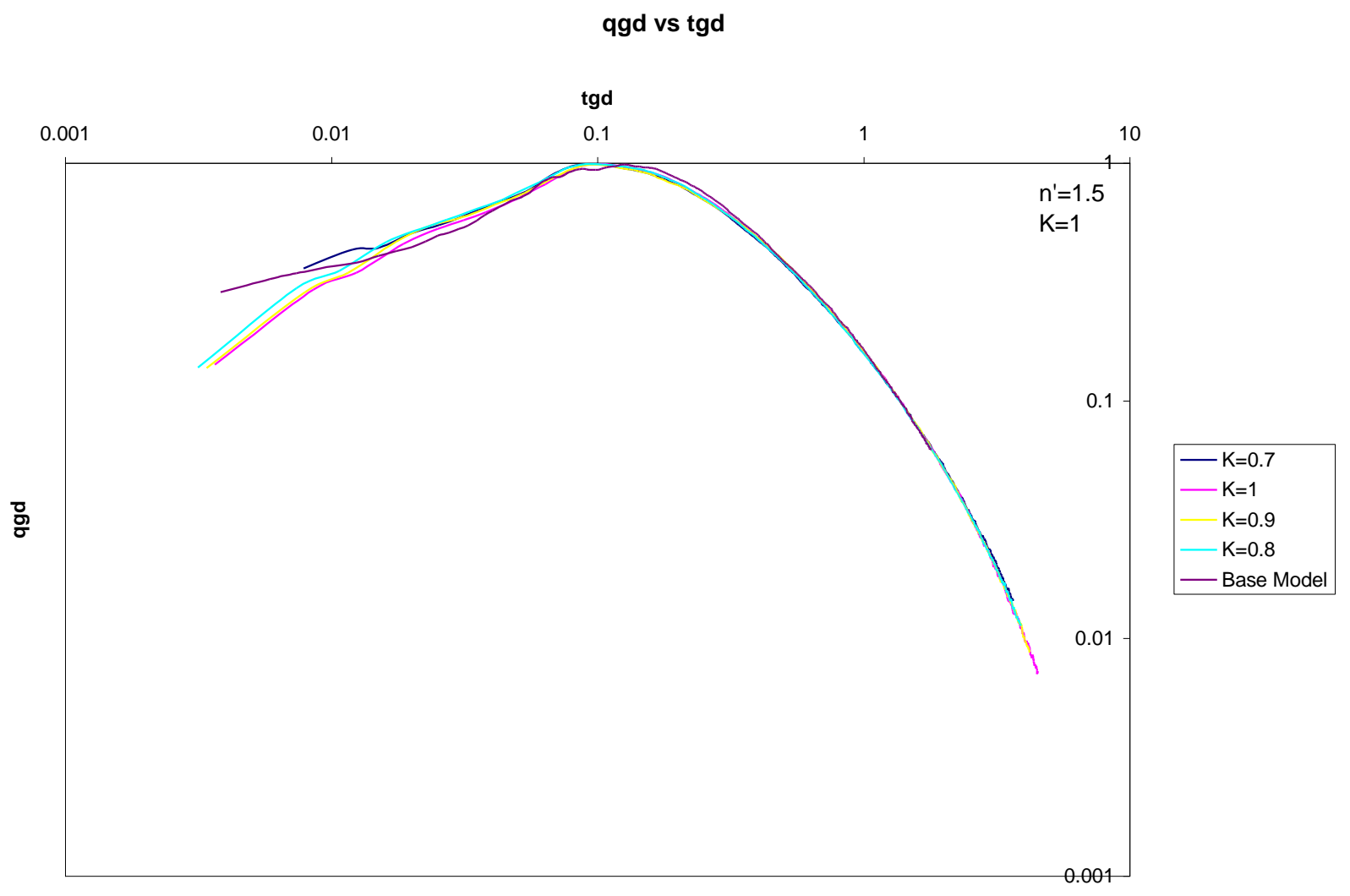

Figure 4.6. $L$ og-L og curve of $q_{g d}$ versus $t_{g d}$ to study the effect of $K$

The values of $\mathrm{n} \square$ and $\mathrm{m} \square$ were kept at a constant value of 1.5 and 1 respectively. $\mathrm{K}$ was varied from the range of 0.7-1. From both the Cartesian curve and the curve in the log-log scale, we see that $\mathrm{K}$ doesn $\square \mathrm{t}$ affect the production of gas in a major way.

The water production also didn\t seem to vary much with the effect of $\mathrm{K}$. The results for water production are shown on both the Cartesian and logarithmic scale in figures 4.7 and 4.8 . 
qwd Vs twd

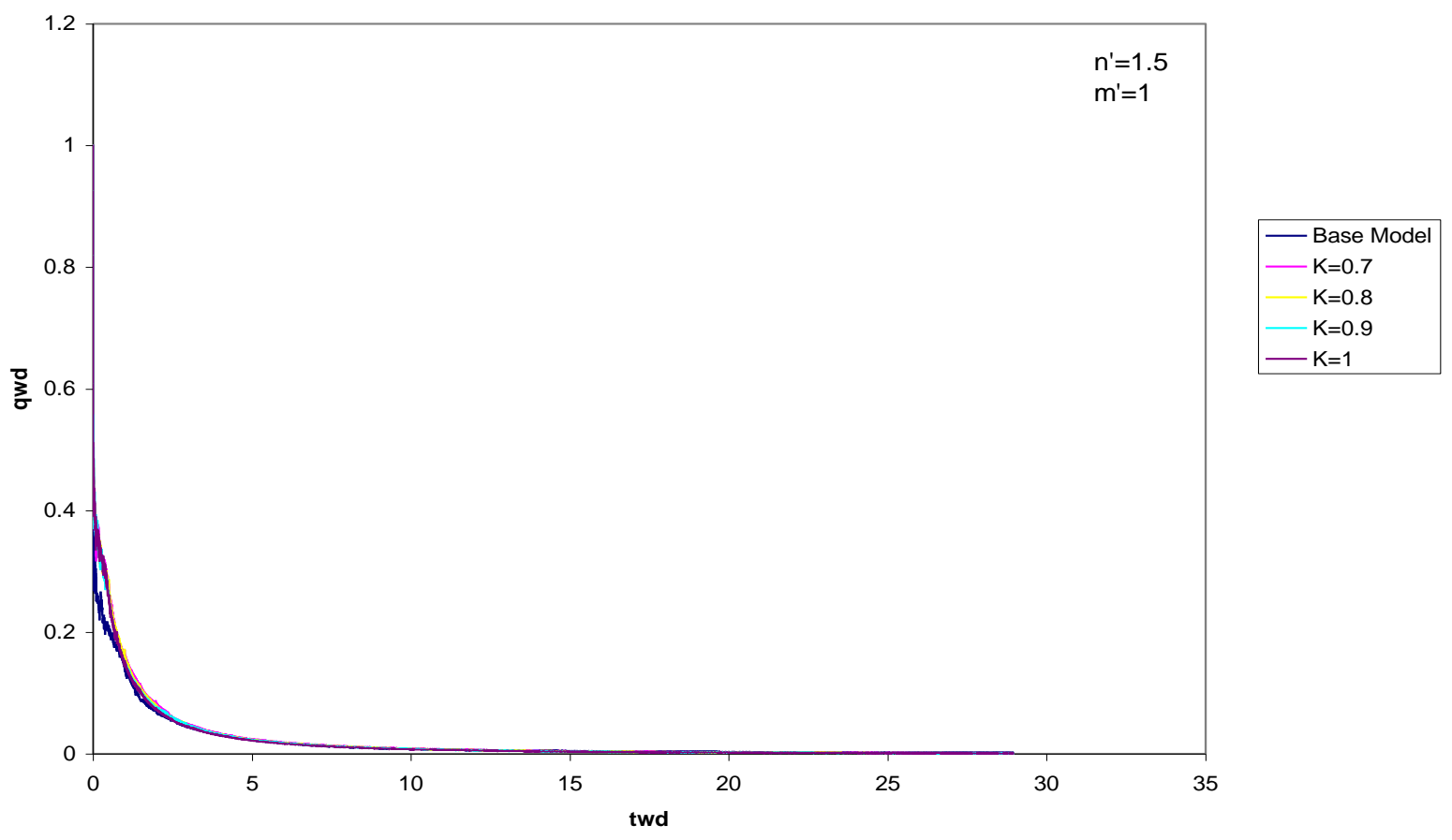

Figure 4.7. C artesian curve of $q_{w d}$ versus $t_{w d}$ to study the effect of $K$

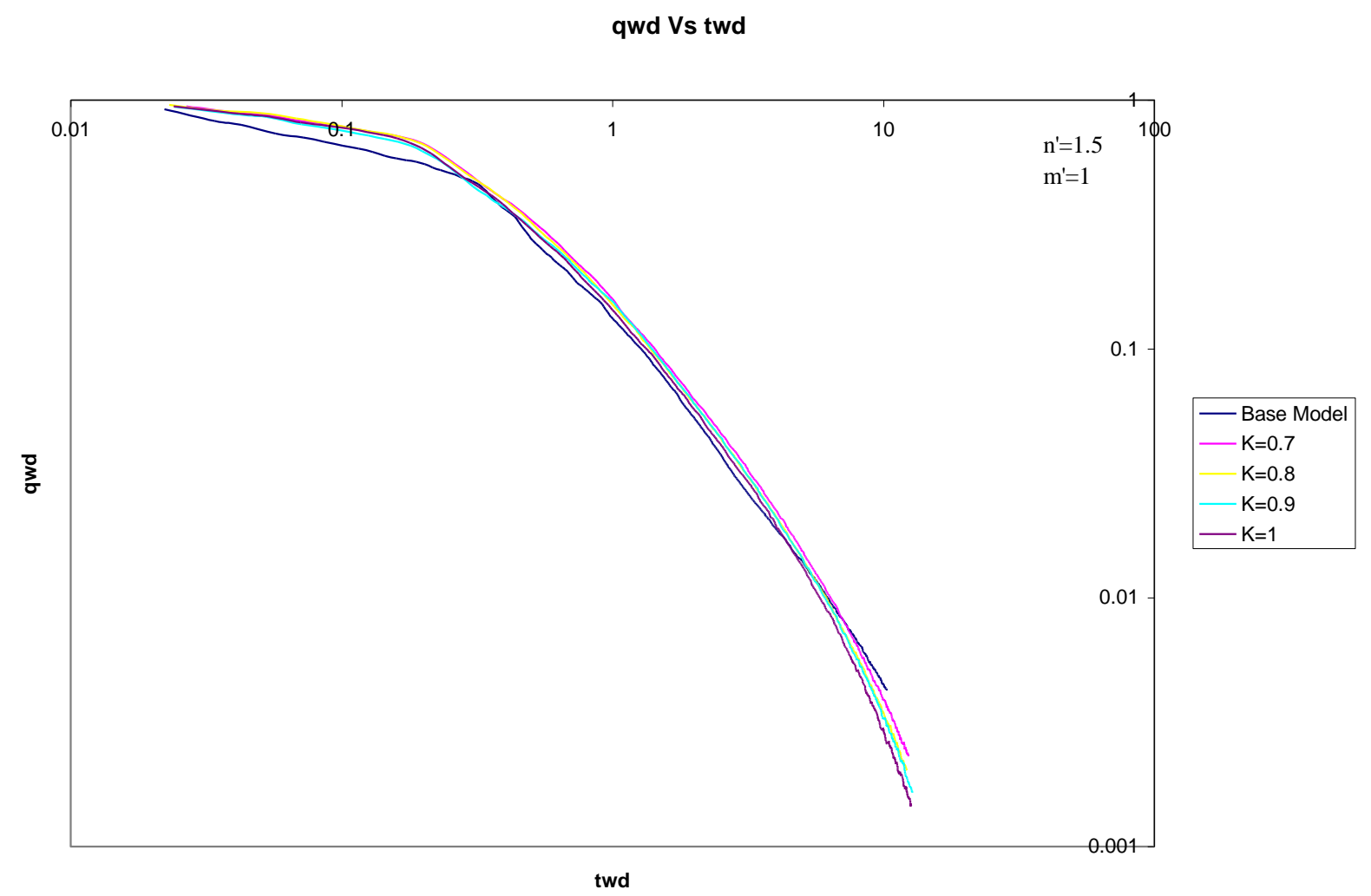

Figure 4.8. L ogarithmic curve of $q_{w d}$ versus $t_{w d}$ to study the effect of $K$ 


\subsection{Effect of constant $m$ '}

The effect of $\mathrm{m} \square$ seemed to be more significant with the gas curves. As the value of $\mathrm{m} \square$ increased, the production of the reservoir slowed down. . The relative permeability values for different values of $\mathrm{m} \square$ are shown in tables 4.5, 4.6 and 4.7. The relative permeability curves for different values of $\mathrm{K}$ are shown in figures 4.9, 4.10 and 4.11. The effect of the values of $\mathrm{m} \square$ is shown in figures 4.12 and 4.13 .

Table 4.5. R elative permeability values for $\mathrm{m}^{\prime}=\mathbf{1}\left(\mathrm{n}^{\prime}=1.5, K=0.7\right)$

\begin{tabular}{|r|r|r|r|}
\hline \multicolumn{1}{|l|}{ Sw* } & \multicolumn{1}{l|}{ Sw } & \multicolumn{1}{l|}{ Krg } \\
\hline 0 & 0 & 0 & 0.7 \\
\hline 0 & 0.1 & 0 & 0.7 \\
\hline 0.2222222 & 0.3 & 0.104757 & 0.544444 \\
\hline 0.4444444 & 0.5 & 0.296296 & 0.388889 \\
\hline 0.6666667 & 0.7 & 0.544331 & 0.233333 \\
\hline 0.8888889 & 0.9 & 0.838052 & 0.077778 \\
\hline 1 & 1 & 1 & 0 \\
\hline
\end{tabular}

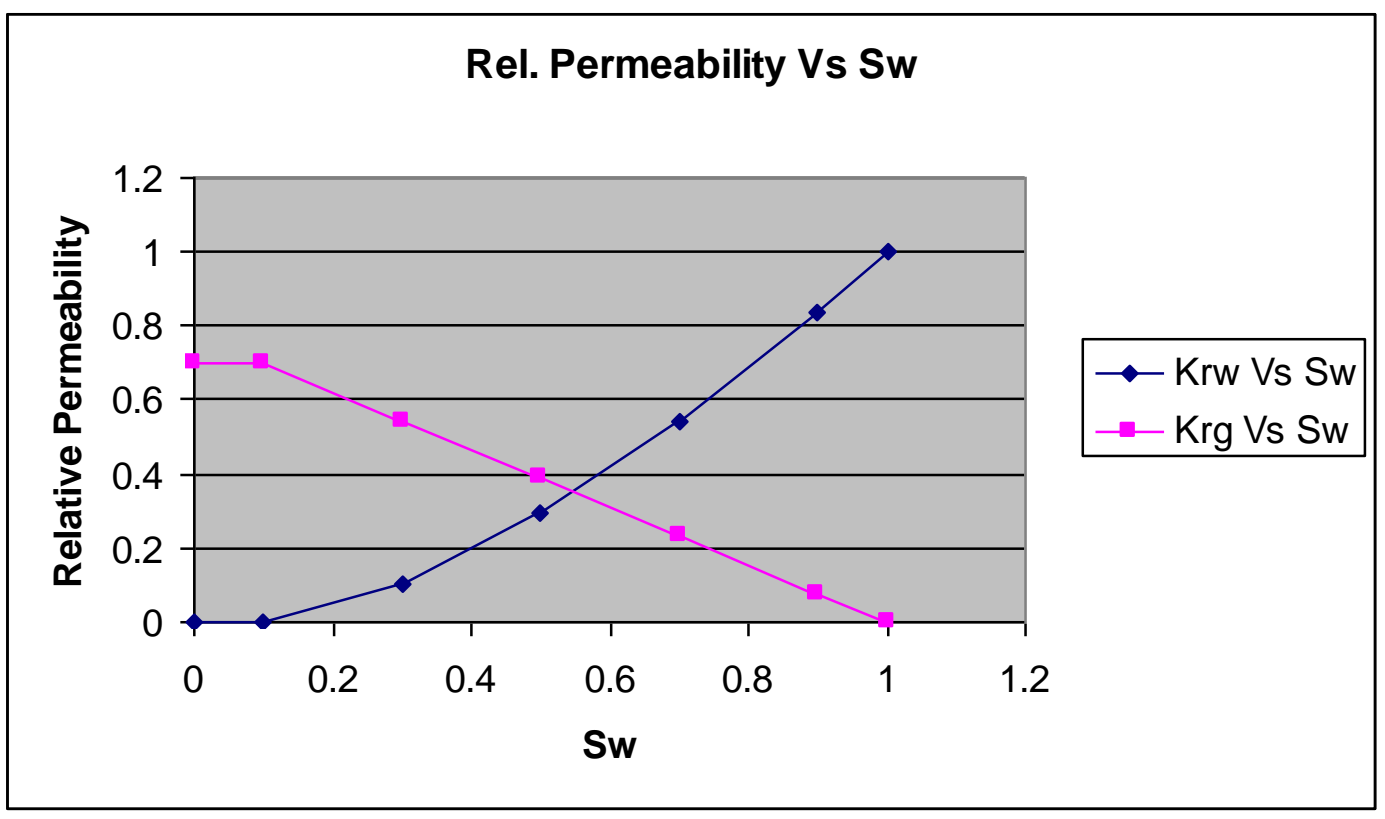

Figure 4.9. R elative permeability curves for $m^{\prime}=1\left(n^{\prime}=1.5, K=0.7\right)$ 
Table 4.6. R elative permeability values for $\mathrm{m}^{\prime}=2\left(\mathrm{n}^{\prime}=1.5, \mathrm{~K}=0.7\right)$

\begin{tabular}{|r|r|r|r|}
\hline \multicolumn{1}{|l|}{ Sw* } & \multicolumn{1}{l|}{ Sw } & \multicolumn{1}{l|}{ Krg } \\
\hline 0 & 0 & 0 & 0.7 \\
\hline 0 & 0.1 & 0 & 0.7 \\
\hline 0.2222222 & 0.3 & 0.104757 & 0.423457 \\
\hline 0.4444444 & 0.5 & 0.296296 & 0.216049 \\
\hline 0.6666667 & 0.7 & 0.544331 & 0.077778 \\
\hline 0.8888889 & 0.9 & 0.838052 & 0.008642 \\
\hline 1 & 1 & 1 & 0 \\
\hline
\end{tabular}

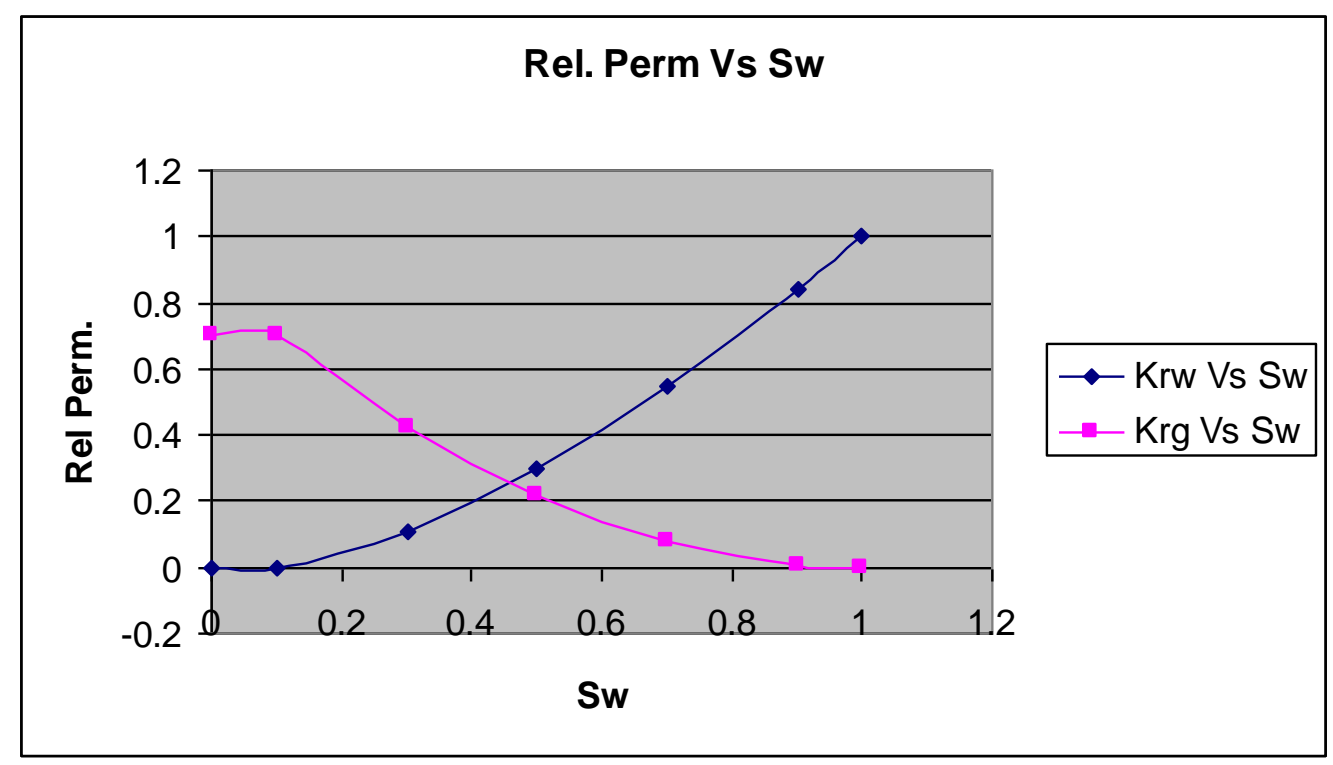

Figure 4.10. R elative permeability curves for $m^{\prime}=2\left(n^{\prime}=1.5, K=0.7\right)$

Table 4.7. R elative permeability values for $\mathrm{m}^{\prime}=3\left(\mathrm{n}^{\prime}=1.5, K=0.7\right)$

\begin{tabular}{|r|r|r|r|}
\hline \multicolumn{1}{|l|}{ Sw* } & \multicolumn{1}{l|}{ Sw } & \multicolumn{1}{l|}{ Krg } \\
\hline 0 & 0 & 0 & 0.7 \\
\hline 0 & 0.1 & 0 & 0.7 \\
\hline 0.2222222 & 0.3 & 0.104757 & 0.329355 \\
\hline 0.4444444 & 0.5 & 0.296296 & 0.120027 \\
\hline 0.6666667 & 0.7 & 0.544331 & 0.025926 \\
\hline 0.8888889 & 0.9 & 0.838052 & 0.00096 \\
\hline 1 & 1 & 1 & 0 \\
\hline
\end{tabular}




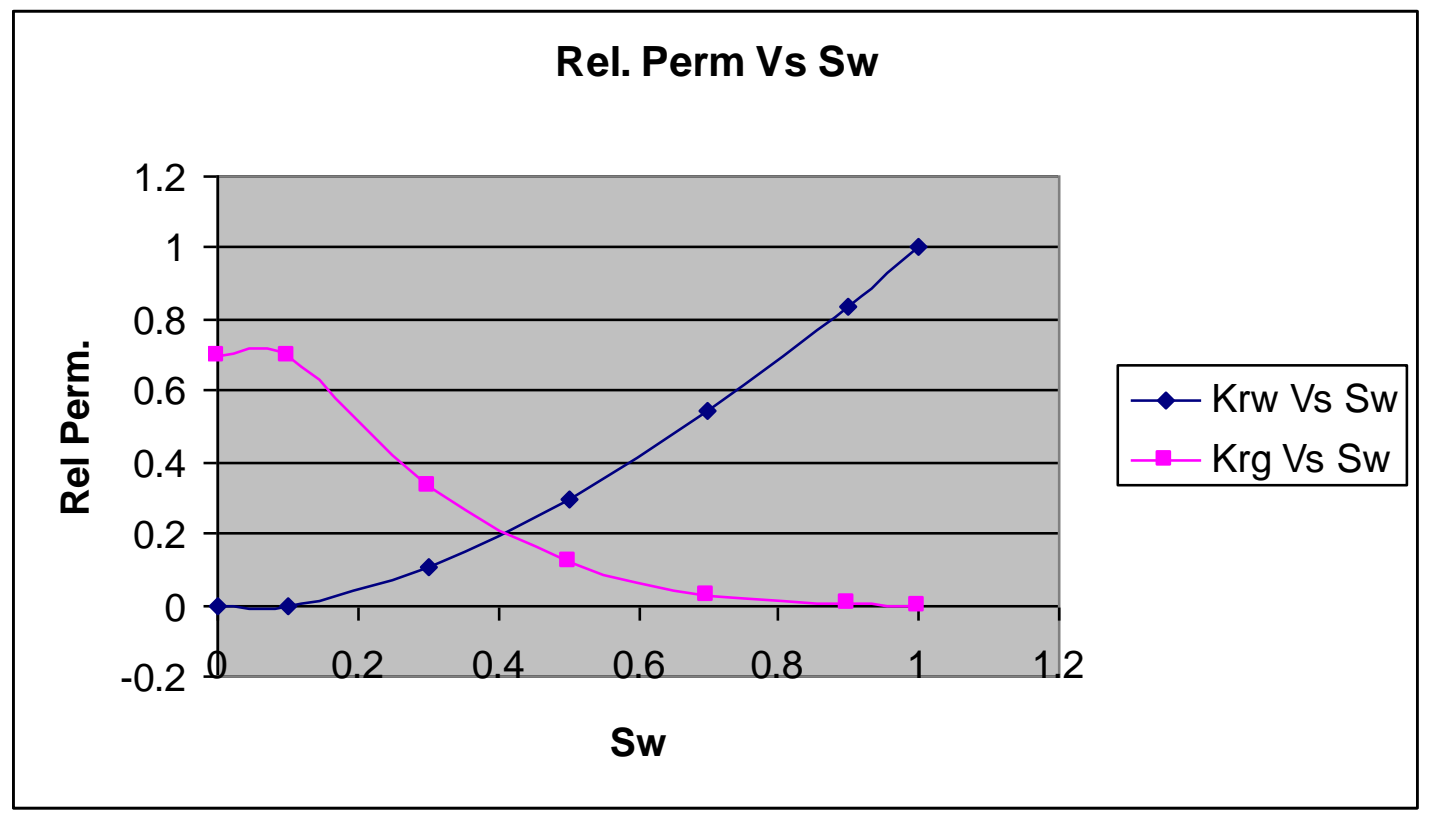

Figure 4.11. R elative permeability curves for $m^{\prime}=3\left(n^{\prime}=1.5, K=0.7\right)$

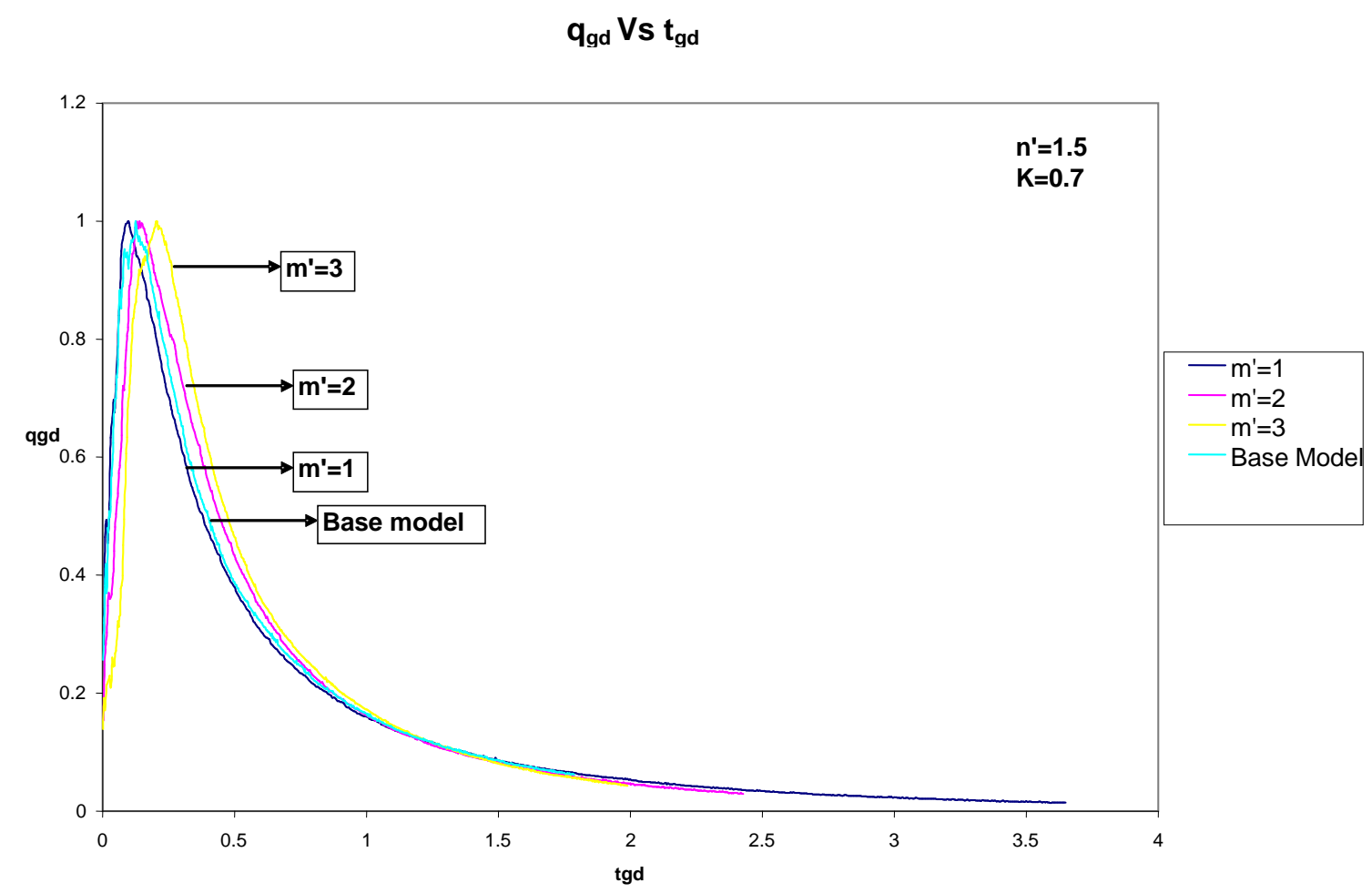

Figure 4.12. Cartesian curve of $q_{g d}$ versus $t_{g d}$ to study the effect of $\mathbf{m}^{\prime}$ 


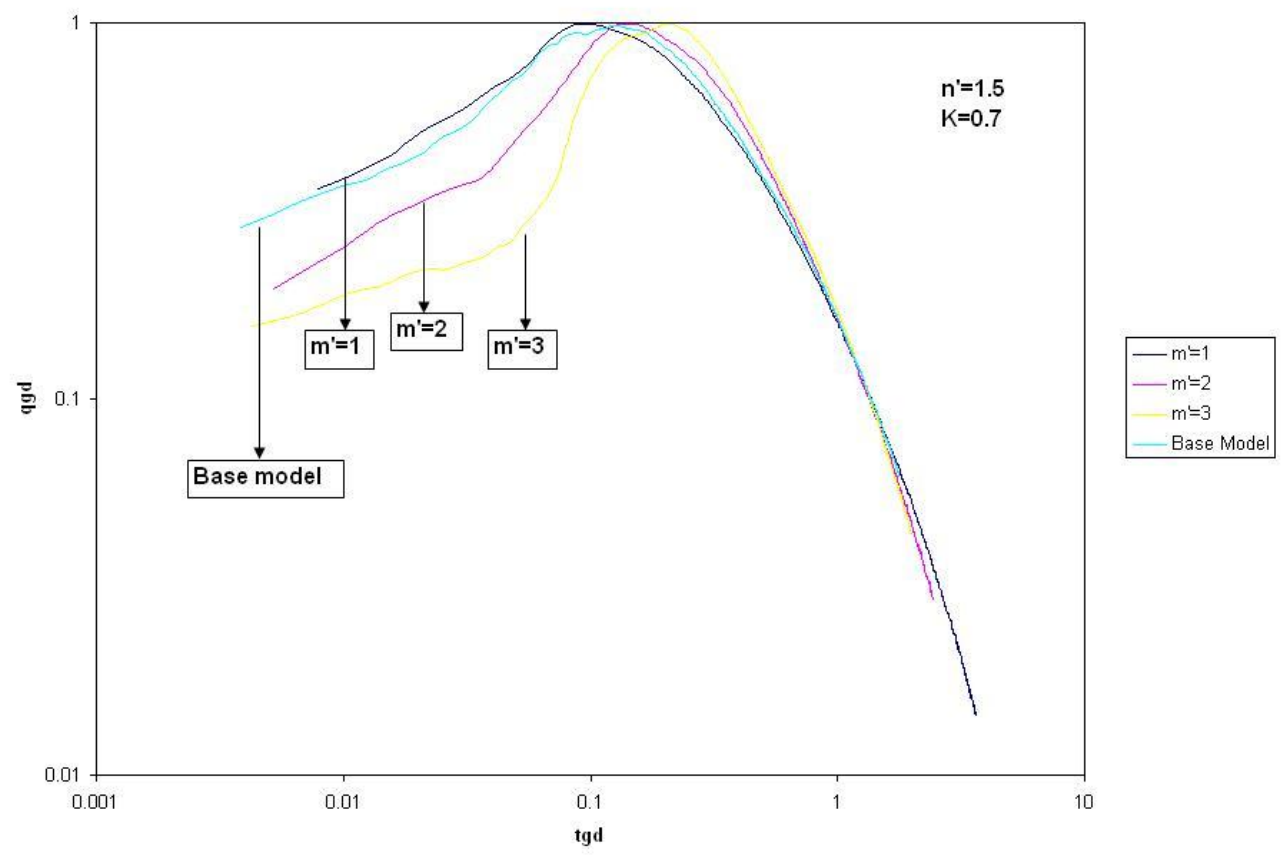

Figure 4.13. L ogarithmic curve of $q_{g d}$ versus $t_{g d}$ to study the effect of $\mathbf{~ m}$

The effect of $\mathrm{m} \square$ on the water curves seemed less significant and negligible when compared to those of the gas curves. The effect of $\mathrm{m} \square$ on the water curves is shown in Figures 4.14 and 4.15 .

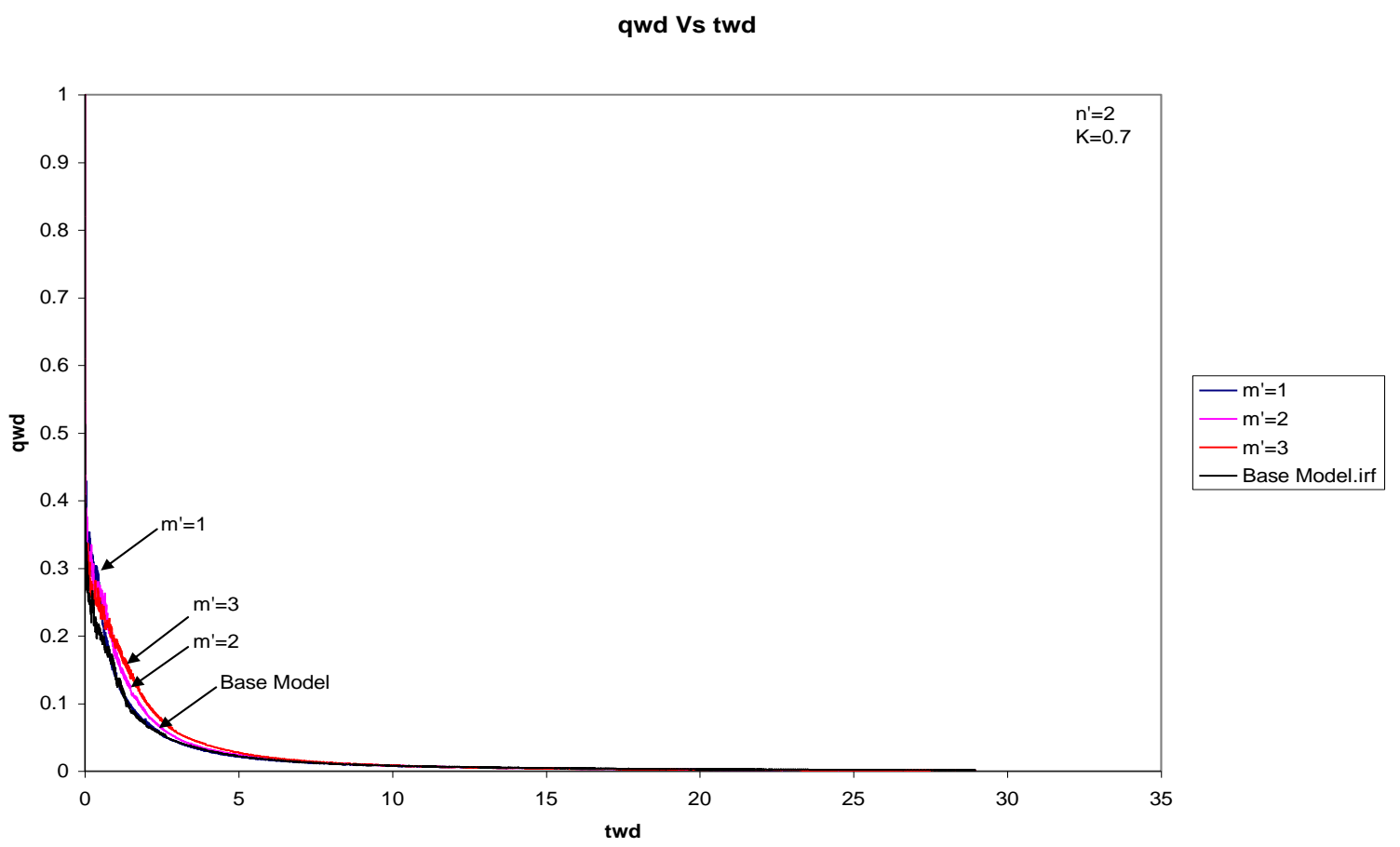

Figure 4.14. C artesian curve of $q_{w d}$ versus $t_{w d}$ to study the ffect of $\mathbf{m}^{\prime}$ 


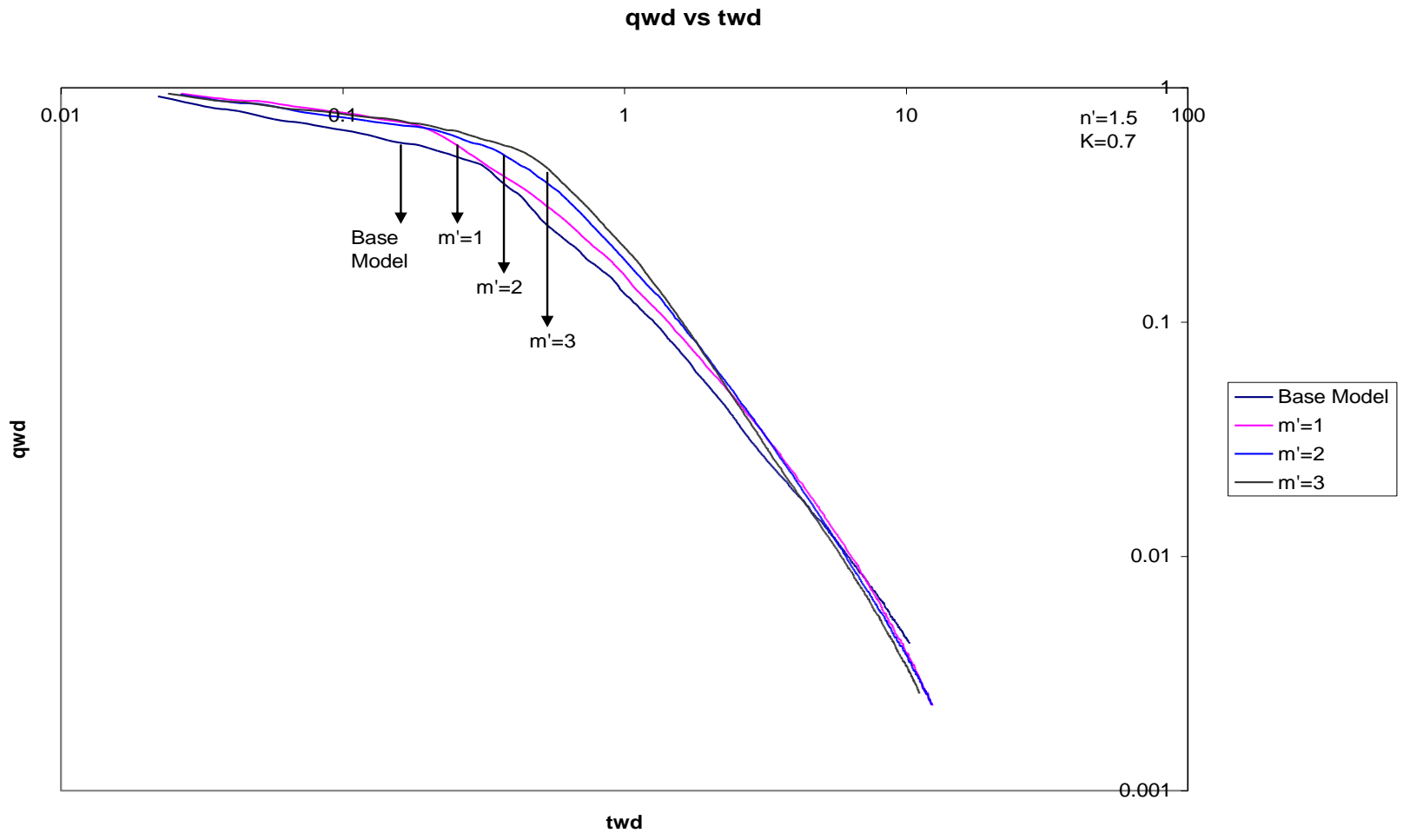

Figure 4.15. L ogarithmic curve of $q_{w d}$ versus $t_{w d}$ to shudy the effect of $\mathbf{m}$ '

\subsection{Effect of constant $n^{\prime}$}

The range of study for $\mathrm{n} \square$ was quite large compared to $\mathrm{m} \square$ and $\mathrm{K}$. When studying the impact of $\mathrm{n} \square$, the variation in the water curves for the extreme ranges seemed very significant. Whereas, the variation in the gas curves was comparatively negligible. The relative permeability values for different values of $\mathrm{K}$ are shown in tables 4.8, 4.9, 4.10, 4.11, 4.12 and 4.13. The relative permeability curves for different values of $K$ are shown in figures 4.16, 4.17, 4.18, 4.19, 4.20 and 4.21. The impact of $n \square$ on both the water and gas curves is shown in figures 4.22 and 4.23

Table 4.8. R elative permeability values for $n^{\prime}=1.5\left(m^{\prime}=1, K=0.7\right)$

\begin{tabular}{|r|r|r|r|}
\hline \multicolumn{1}{|l|}{ Sw* } & \multicolumn{1}{l|}{ Sw } & \multicolumn{1}{l|}{ Krw } \\
\hline 0 & 0 & 0 & 0.7 \\
\hline 0 & 0.1 & 0 & 0.7 \\
\hline 0.2222222 & 0.3 & 0.104757 & 0.544444 \\
\hline 0.4444444 & 0.5 & 0.296296 & 0.388889 \\
\hline 0.6666667 & 0.7 & 0.544331 & 0.233333 \\
\hline 0.8888889 & 0.9 & 0.838052 & 0.077778 \\
\hline 1 & 1 & 1 & 0 \\
\hline
\end{tabular}




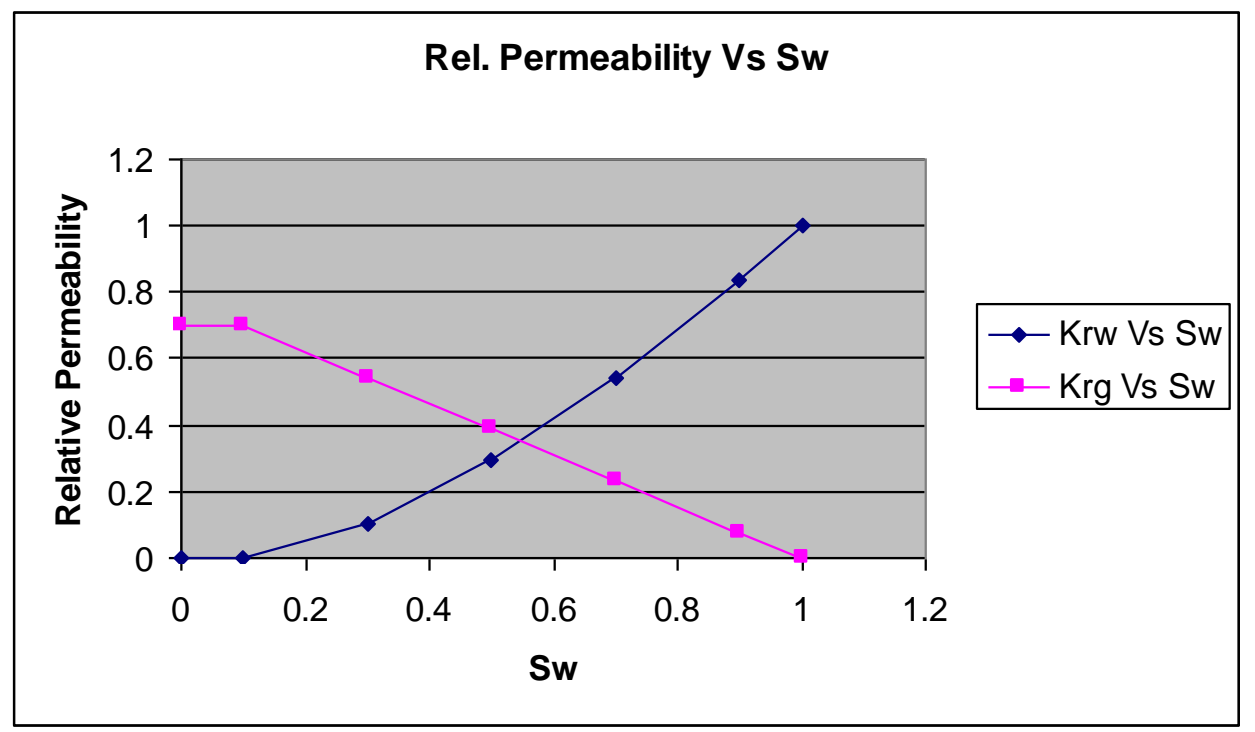

Figure 4.16. R elative permeability curves for $n^{\prime}=1.5\left(m^{\prime}=1, K=0.7\right)$

Table 4.9. R elativepermeability values for $n^{\prime}=2\left(m^{\prime}=1, K=0.7\right)$

\begin{tabular}{|r|r|r|r|}
\hline \multicolumn{1}{|l|}{ Sw* } & \multicolumn{1}{l|}{ Krw } & \multicolumn{1}{l|}{ Krg } \\
\hline 0 & 0 & 0 & 0.7 \\
\hline 0 & 0.1 & 0 & 0.7 \\
\hline 0.2222222 & 0.3 & 0.049383 & 0.544444 \\
\hline 0.4444444 & 0.5 & 0.197531 & 0.388889 \\
\hline 0.6666667 & 0.7 & 0.444444 & 0.233333 \\
\hline 0.8888889 & 0.9 & 0.790123 & 0.077778 \\
\hline 1 & 1 & 1 & 0 \\
\hline
\end{tabular}

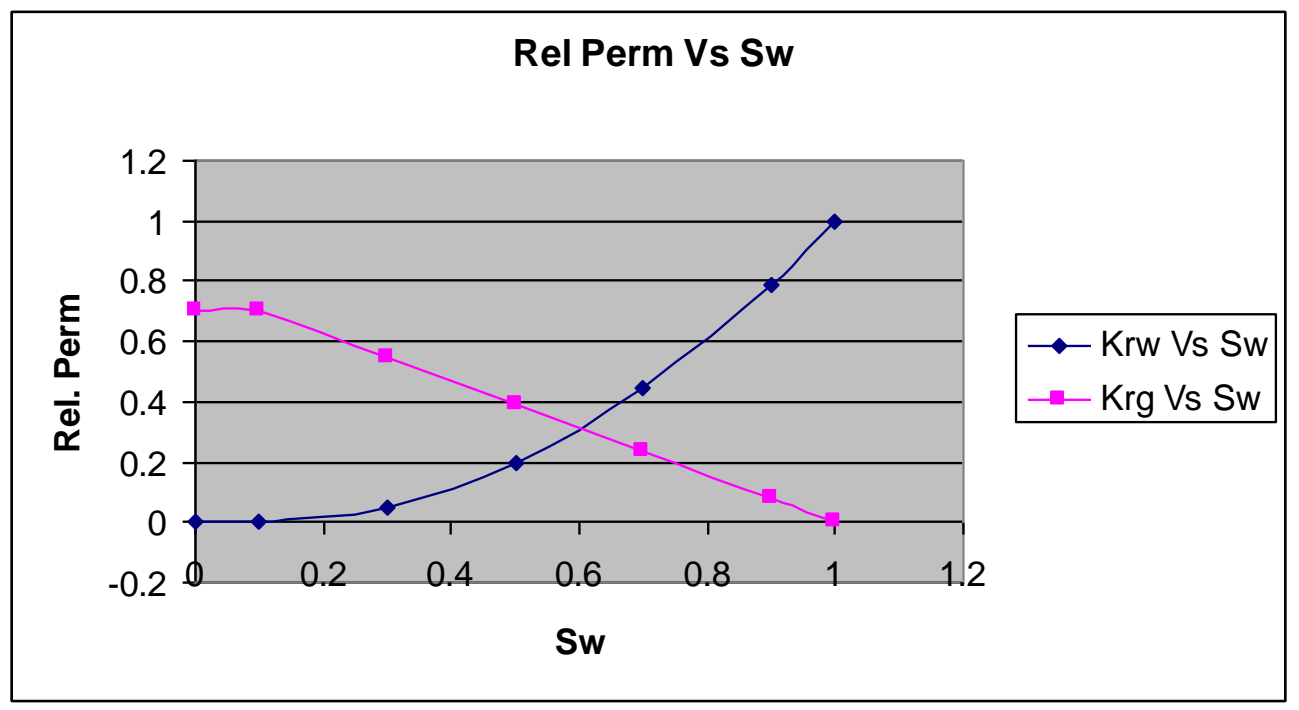

Figure 4.17. R elative permeability arves for $n^{\prime}=2\left(m^{\prime}=1, K=0.7\right)$ 
Table 4.10. R elative permeability values for $n^{\prime}=3\left(m^{\prime}=1, K=0.7\right)$

\begin{tabular}{|r|r|r|r|}
\hline \multicolumn{1}{|l|}{ Sw* } & \multicolumn{1}{l|}{ Sw } & \multicolumn{1}{l|}{ Krg } \\
\hline 0 & 0 & 0 & 0.7 \\
\hline 0 & 0.1 & 0 & 0.7 \\
\hline 0.2222222 & 0.3 & 0.010974 & 0.544444 \\
\hline 0.4444444 & 0.5 & 0.087791 & 0.388889 \\
\hline 0.6666667 & 0.7 & 0.296296 & 0.233333 \\
\hline 0.8888889 & 0.9 & 0.702332 & 0.077778 \\
\hline 1 & 1 & 1 & 0 \\
\hline
\end{tabular}

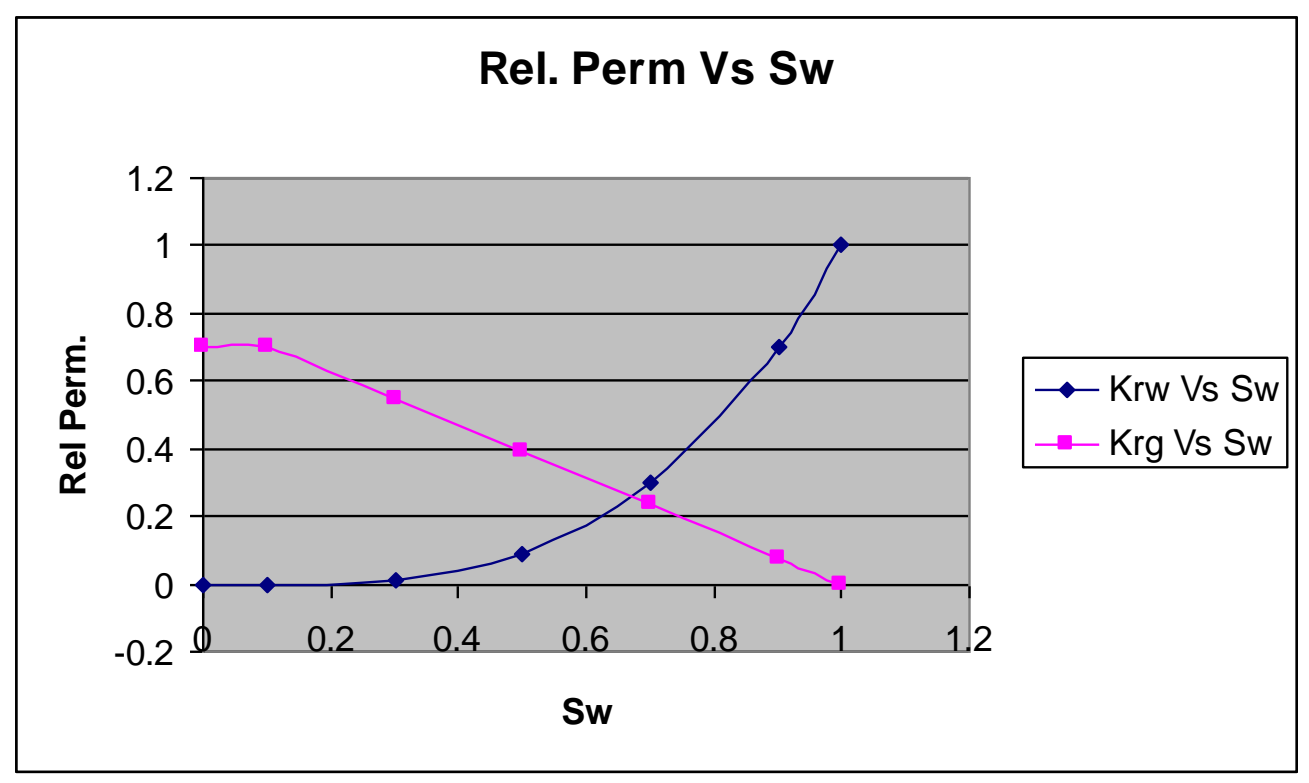

Figure 4.18. R elative permeability arves for $n^{\prime}=3\left(m^{\prime}=1, K=0.7\right)$

Table 4.11. R elative permeability values for $n^{\prime}=4\left(m^{\prime}=1, K=0.7\right)$

\begin{tabular}{|r|r|r|r|}
\hline \multicolumn{1}{|l|l|l|}{ Sw* } & \multicolumn{1}{l|}{ Krw } & \multicolumn{1}{l|}{ Krg } \\
\hline 0 & 0 & 0 & 0.7 \\
\hline 0 & 0.1 & 0 & 0.7 \\
\hline 0.2222222 & 0.3 & 0.002439 & 0.544444 \\
\hline 0.4444444 & 0.5 & 0.039018 & 0.388889 \\
\hline 0.6666667 & 0.7 & 0.197531 & 0.233333 \\
\hline 0.8888889 & 0.9 & 0.624295 & 0.077778 \\
\hline 1 & 1 & 1 & 0 \\
\hline
\end{tabular}




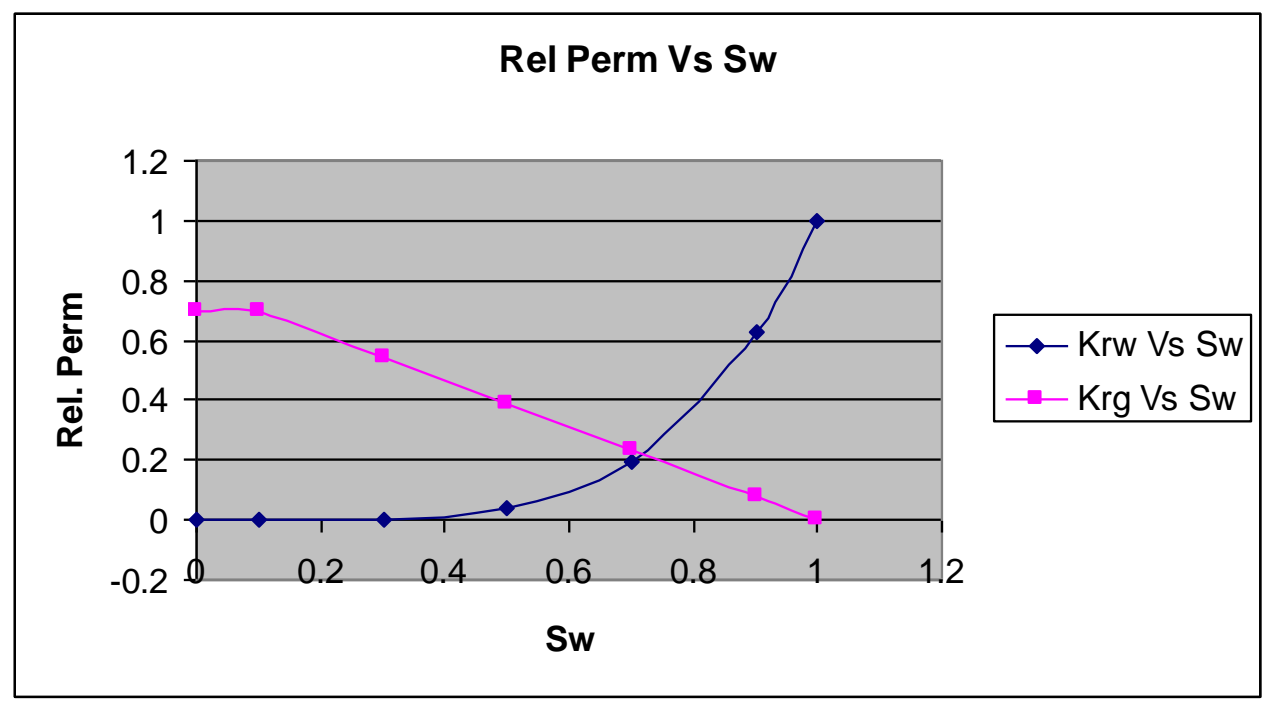

Figure 4.19. R elative permeability arves for $n^{\prime}=4\left(m^{\prime}=1, K=0.7\right)$

Table 4.12. R elative permebility values for $n^{\prime} \Rightarrow\left(m^{\prime}=1, K=0.7\right)$

\begin{tabular}{|r|r|r|r|}
\hline \multicolumn{1}{|l|}{ Sw* } & Sw & \multicolumn{1}{l|}{ Krw } & \multicolumn{1}{l|}{ Krg } \\
\hline 0 & 0 & 0 & 0.7 \\
\hline 0 & 0.1 & 0 & 0.7 \\
\hline 0.2222222 & 0.3 & 0.000542 & 0.544444 \\
\hline 0.4444444 & 0.5 & 0.017342 & 0.388889 \\
\hline 0.6666667 & 0.7 & 0.131687 & 0.233333 \\
\hline 0.8888889 & 0.9 & 0.554929 & 0.077778 \\
\hline 1 & 1 & 1 & 0 \\
\hline
\end{tabular}

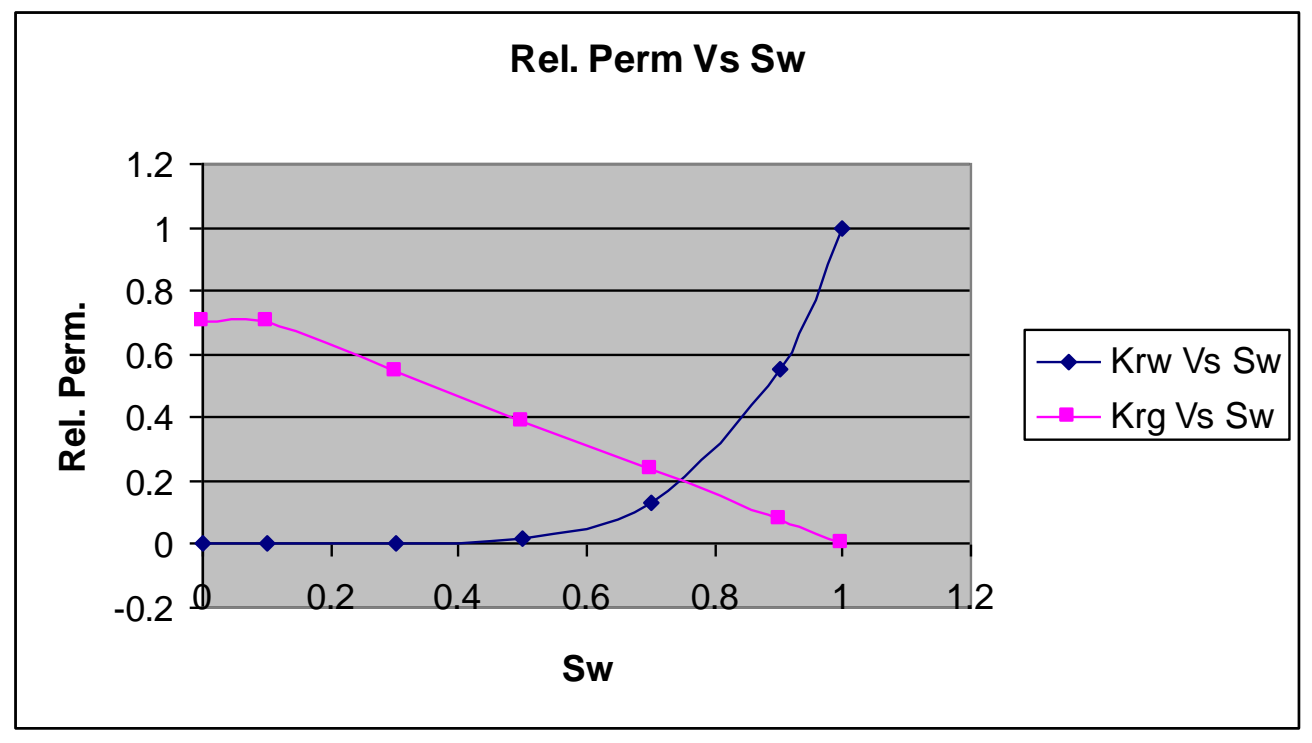

Figure 4.20. R elative permeability arves for $n^{\prime}=5\left(m^{\prime}=1, K=0.7\right)$ 
Table 4.12. R elative permeability values for $n^{\prime}=6\left(m^{\prime}=1, K=0.7\right)$

\begin{tabular}{|r|r|r|r|}
\hline \multicolumn{1}{|l|}{ Sw* } & \multicolumn{1}{l|}{ Sw } & \multicolumn{1}{l|}{ Krg } \\
\hline 0 & 0 & 0 & 0.7 \\
\hline 0 & 0.1 & 0 & 0.7 \\
\hline 0.2222222 & 0.3 & 0.00012 & 0.544444 \\
\hline 0.4444444 & 0.5 & 0.007707 & 0.388889 \\
\hline 0.6666667 & 0.7 & 0.087791 & 0.233333 \\
\hline 0.8888889 & 0.9 & 0.49327 & 0.077778 \\
\hline 1 & 1 & 1 & 0 \\
\hline
\end{tabular}

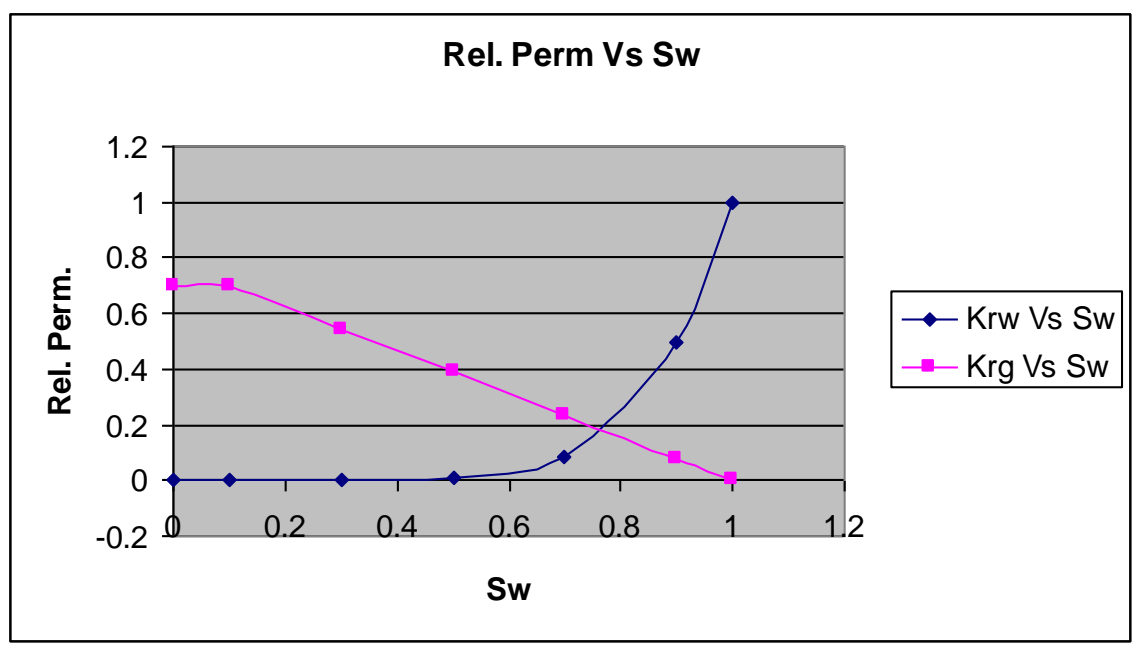

Figure 4.21. R elative permeability arves for $n^{\prime}=6\left(m^{\prime}=1, K=0.7\right)$

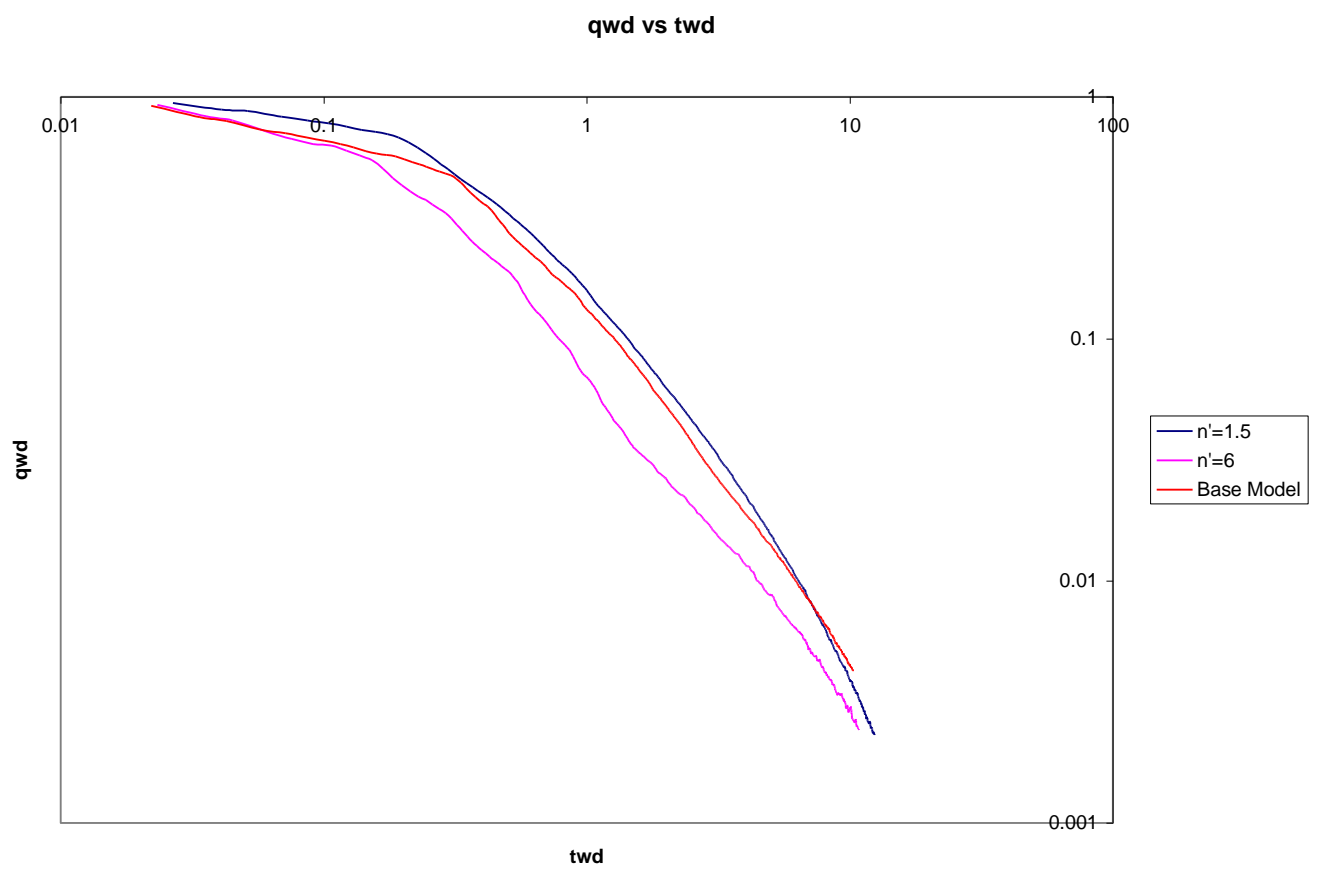

Figure 4.22. Logarithmic curve of $q_{w d}$ versus $t_{w d}$ to shudy the effect of $n$ ' 


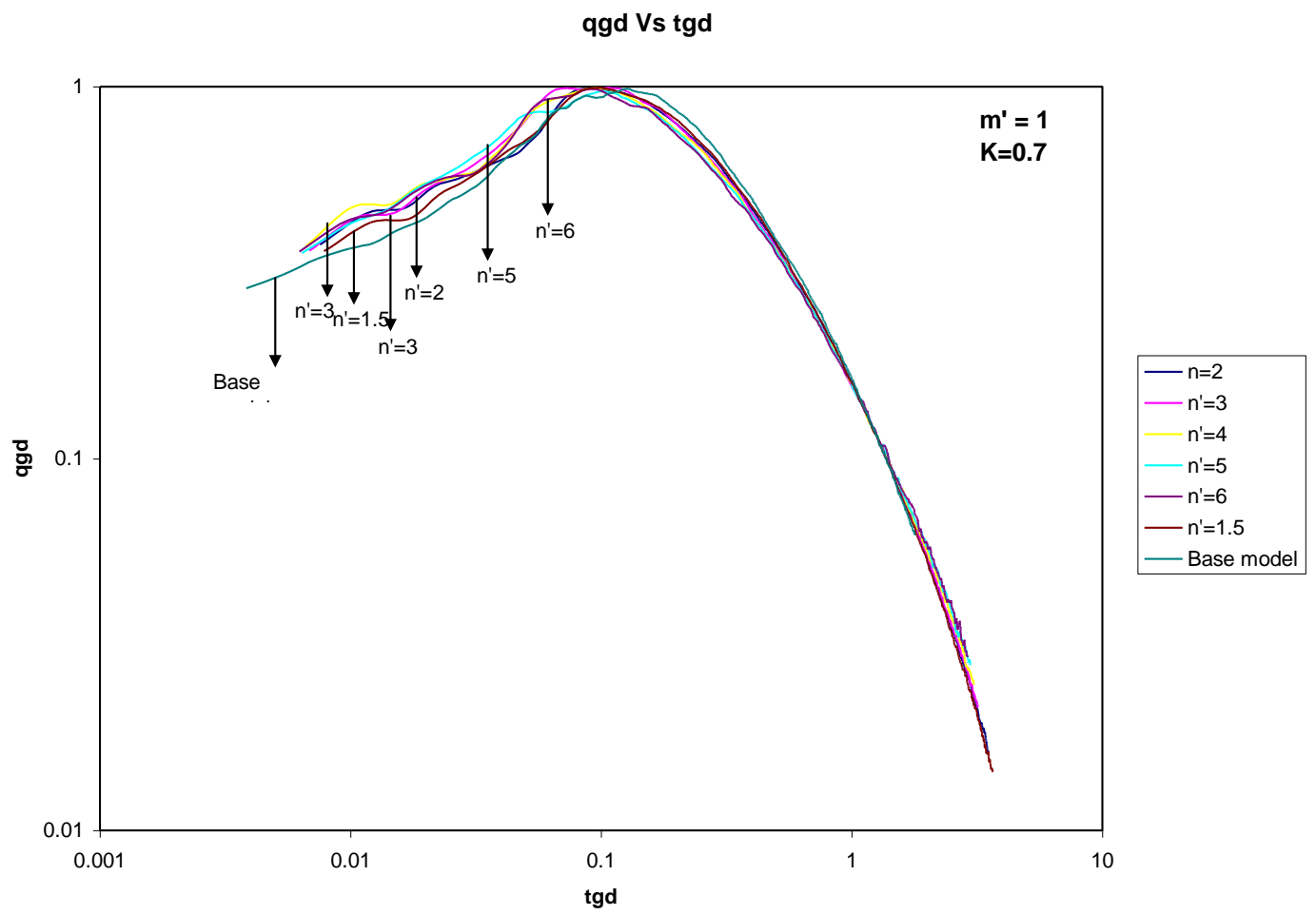

Figure 4.23.L ogarithmic curve of $q_{g d}$ versus $t_{g d}$ to study the effect of $n^{\prime}$ $\left(q_{\text {peak }}\right)_{d}$ Vs n'

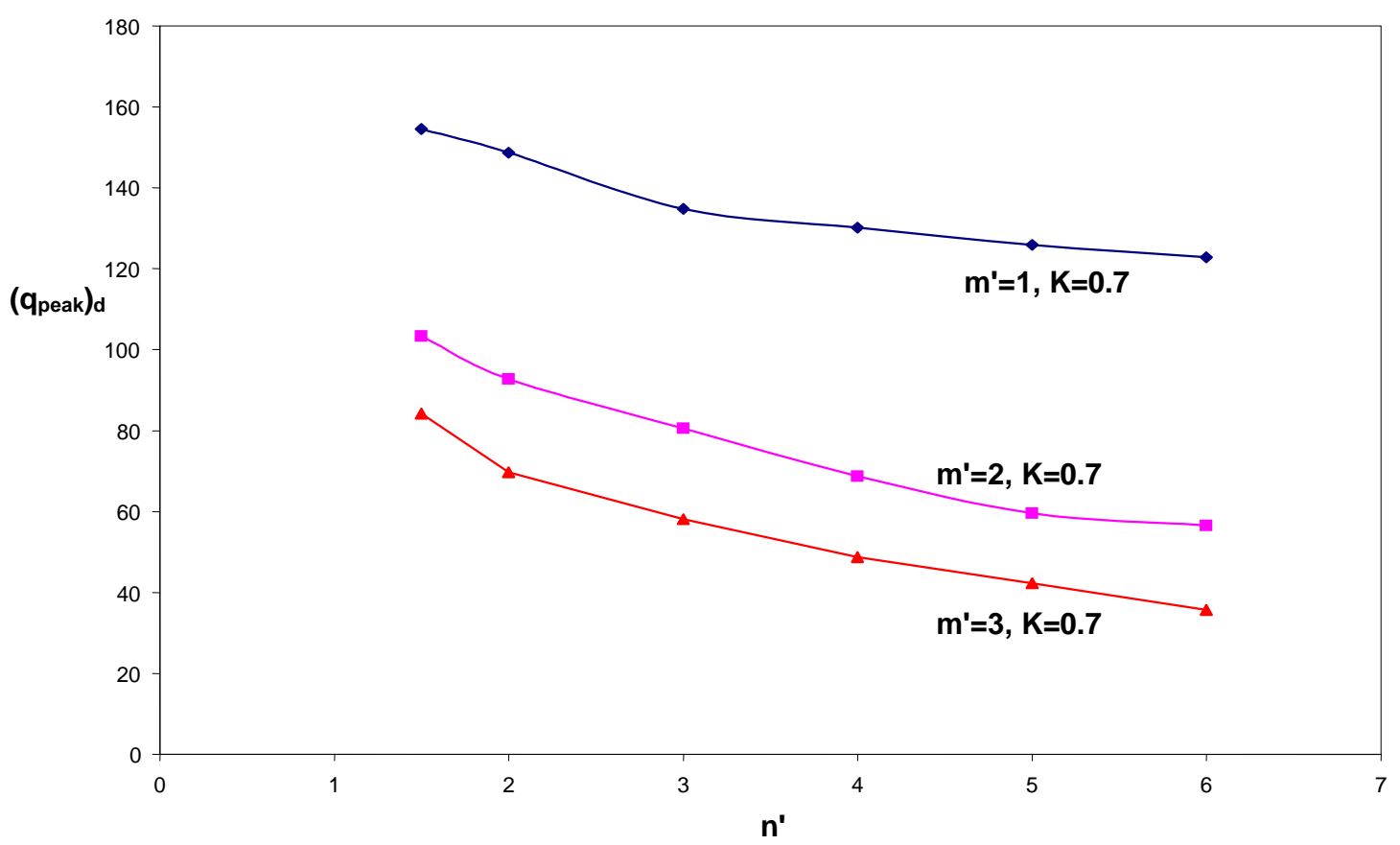

Figure 4.24. I mpact of n' on peak gas rate 


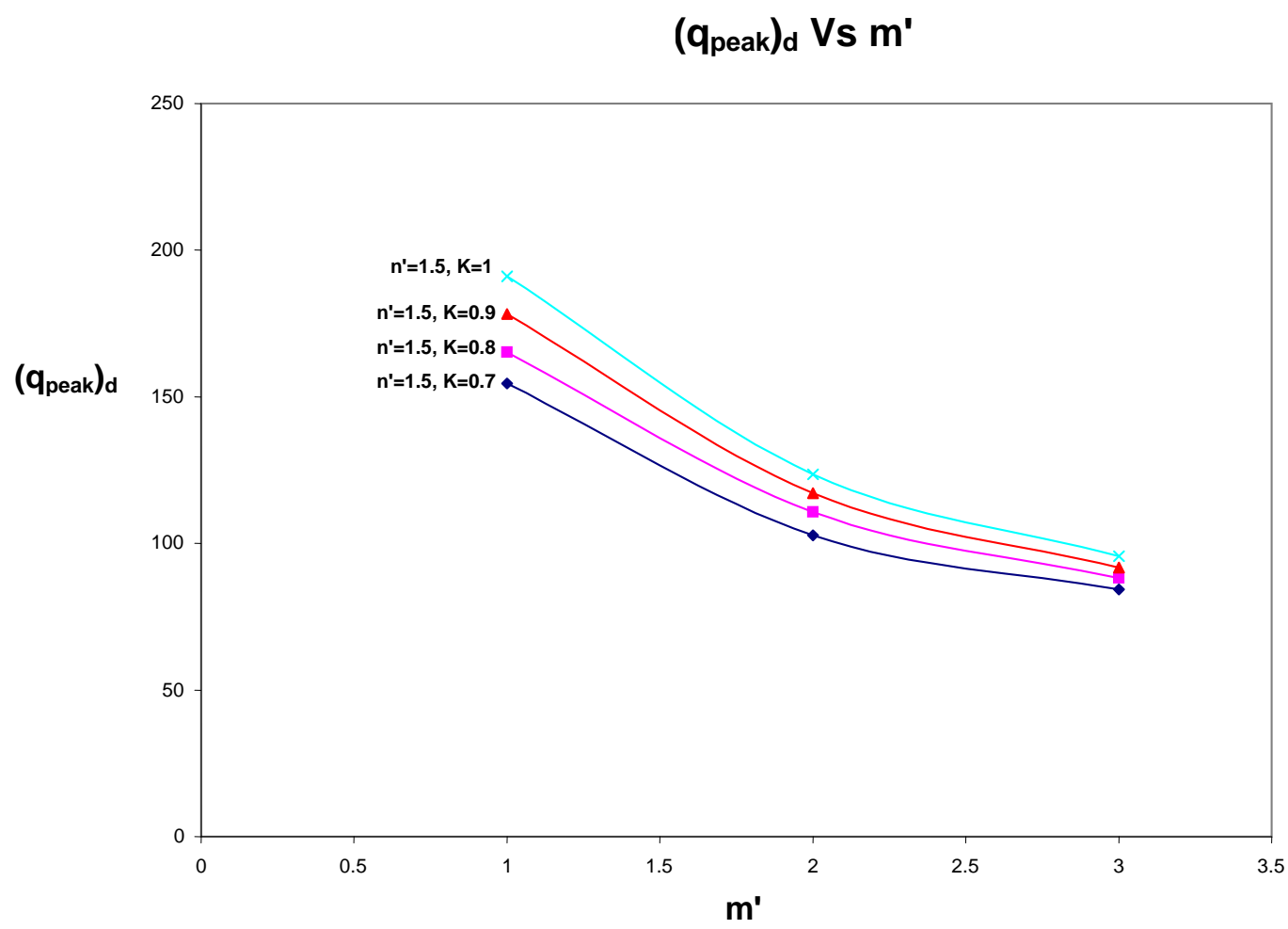

Figure 4.25. I mpact of ' $\mathrm{m}^{\prime}$ on peak gas rate

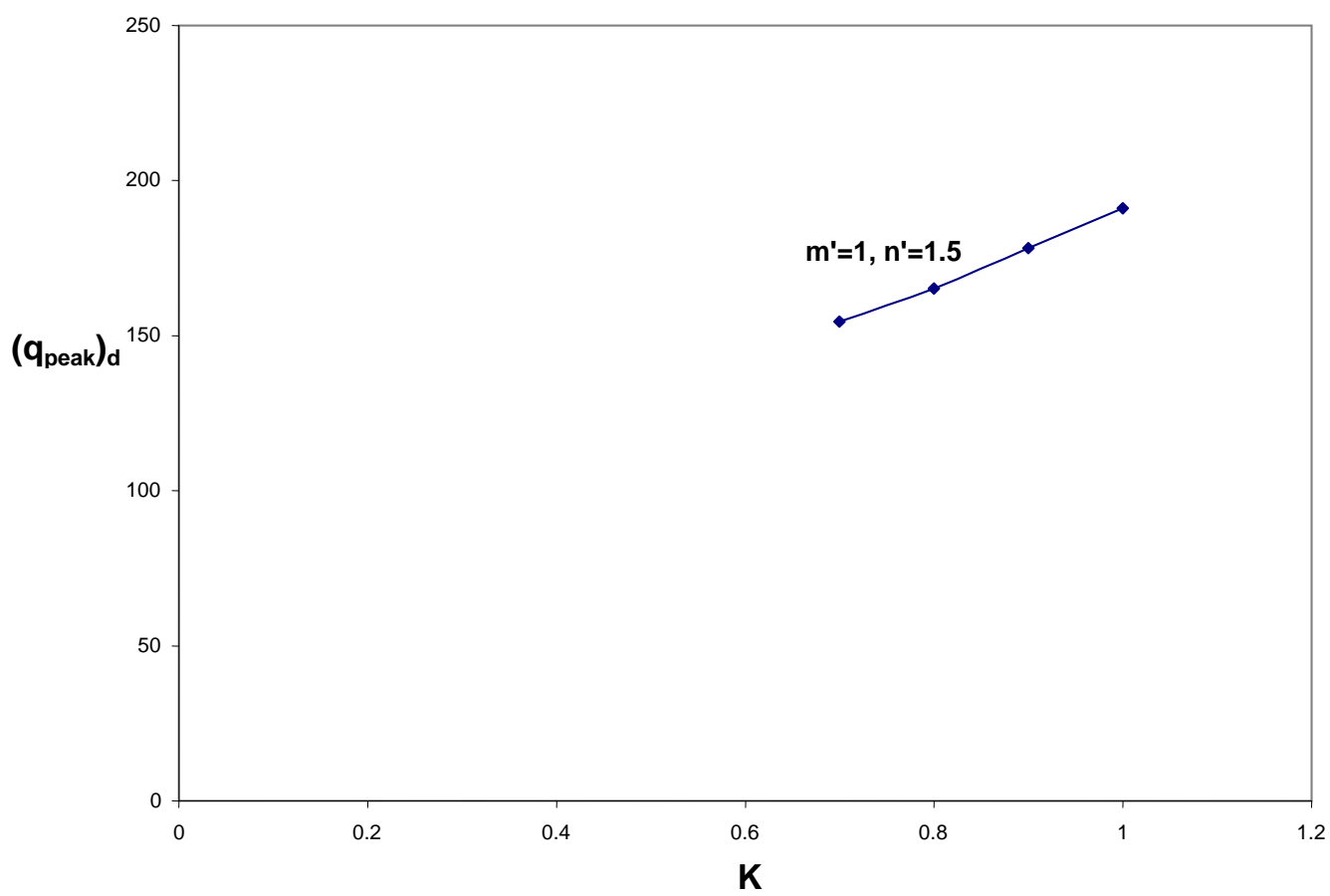

Figure 4.26. Impact of $K$ on peak gas rate 


\section{Gas rate Vs Time}

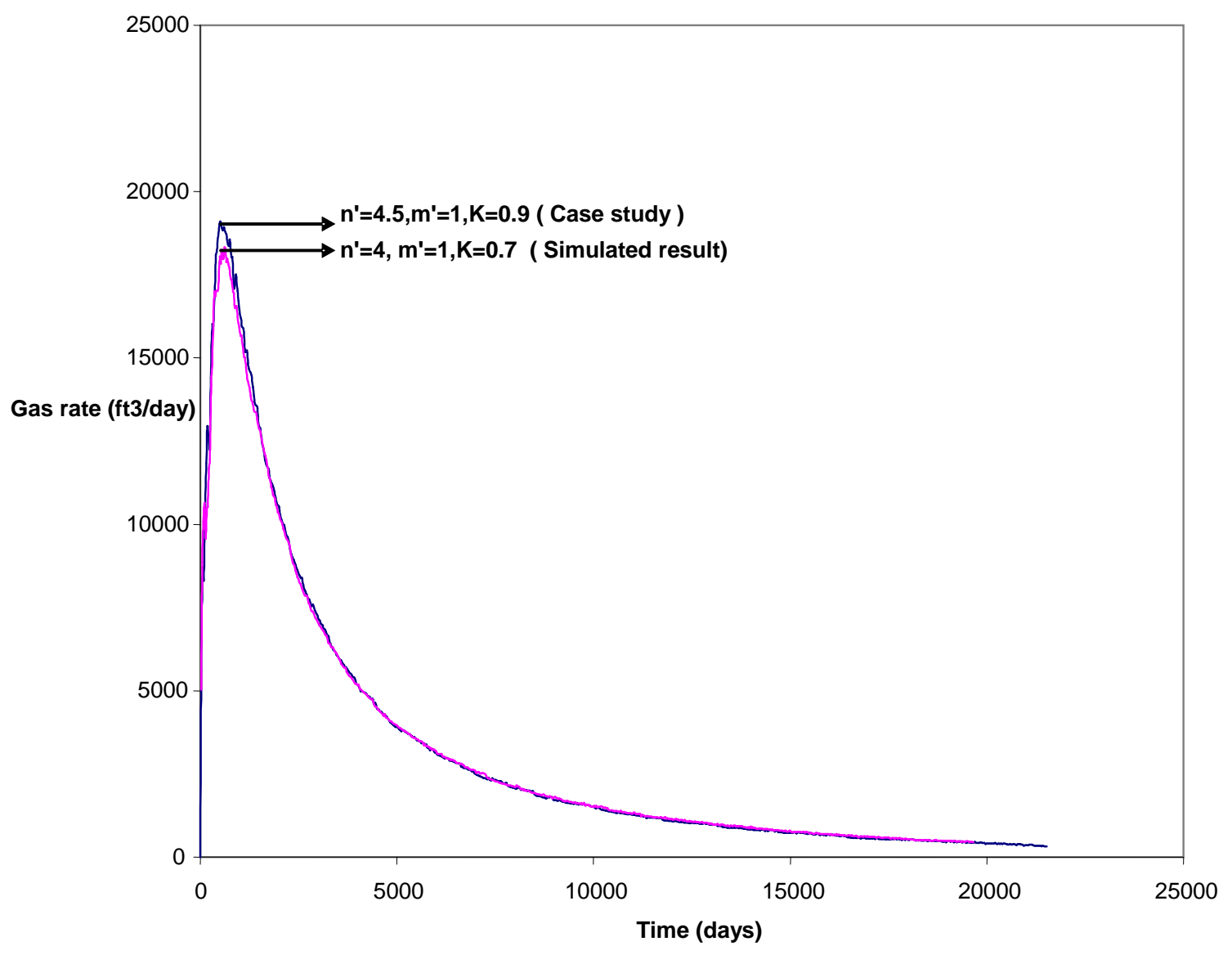

Figure 4.27. C omparison of the predicted model with the original model

As it can be seen from the figures the predicted production rates from the type curves closely match those from simulator. 


\section{CHAPTER 5}

\section{CONCLUSION AND RECOMMENDATIONS}

The gas production type curves based on relative permeability, developed in this study can serve as a quick and simple tool for production data analysis and production prediction analysis. In order to efficiently utilize the type curves for evaluation of a prospect it was necessary to estimate peak gas production rate which led us to development of a correlation for $\left(\mathrm{q}_{\text {peak }}\right)_{g d}$ involving the constants $\mathrm{n} \square, \mathrm{m} \square$ and $\mathrm{K}$.

After studying and analyzing the impact of relative permeability in the production type curve for coalbed methane reservoir, the following conclusions have been reached:

1. The value of constant $\mathrm{K}$ doesn\t affect the performance by any extent.

2. The value of $\mathrm{m} \square$ seemed to be more significant with the gas curves. As the value of $\mathrm{m} \square$ increased, the production of the reservoir slowed down. But, $\mathrm{m} \square$ did not do much to effect the water curves.

3. The value of $\mathrm{n} \square$ seemed to be more significant with the water curves. The variation in the water curves for the extreme ranges seemed very significant. Whereas, the variation in the gas curves was comparatively negligible.

4. A new dimensionless equation which is a function of the constants $\mathrm{n} \square, \mathrm{m} \square$ and $\mathrm{K}$ for gas peak rate was introduced to simplify the development of the correlation.

5. The validation of the correlation between skin $\mathrm{n} \square, \mathrm{m} \square$ and $\mathrm{K}$ for qpeak prediction was performed comparing the outputs from the simulated data. The prediction of gas rate using the correlation showed accurate results with an error less than $10 \%$. 


\section{REFERENCES}

1.) „A Novice's Introduction to Coal Bed methane[

http://waterquality.montana.edu/docs/methane/cbm101.shtml

2.) „A review of CBM in the USロ

http://www.admiralbay.com/global/contentserver/files/1022/151606_A_Review_of_CB

M_in_the US.pdf

3.) „Preliminary Assessment of Worldwide Coalbed Methane Resources【

http://aapg.confex.com/aapg/da2004/techprogram/A88248.htm

4.) „North American Coalbed Methane Resource Map】

http://www.eandpnet.com/mapscharts/cbm/mercator.html

5.) International Energy Outlook. (http://www.eia.doe.gov/oiaf/ieo/coal.html)

6.) BP Statistical Energy Review, June 2005

7.) Coalbed methane fundamental concepts

http://karl.nrcce.wvu.edu/regional/CoalbedMethane_Aminian_Paper_1.pdf

8.) Aminian, K. (2004). “Type Curve for Coalbed Methane Prediction,” SPE 91482, 2004 SPE Eastern Regional Meeting, Charleston, WV

9.)【Canary resources- Coalbed methane[

http://www.canaryresources.com/pages/cbm.htm

10.) „Coalbed Methane--An Untapped Energy Resource and an Environmental Concern $\square$ http://energy.usgs.gov/factsheets/Coalbed/coalmeth.html

11.) 'Coalbed methane in Wyoming- Black Diamond $\square$

energyПhttp://www.blackdiamondenergy.com/coalbed.html

12.) WORC Fact sheet, March 2003, Coal bed methane development.

13.) Coalbed Methane Development Overview, NPS Western Energy Summit, January 21-23, 2003

14.) The Increasing Role of Unconventional Reservoirs in the Future of the Oil and Gas Business, Stephen A. Holditch, Schlumberger www.spe.org/specma/binary/files/1004785unconv_res_holditch2001.pdf

15.) „Technology for coalbed methane in the Appalachian basin!. http://www.pttc.org/solutions/402.htm-Innovative 
16.) Coalbed Natural Gas Resources and Produced Water Management http://www.all-llc.com/CBM/pdf/CoalbedMeth-ProducedWtrMgmt.pdf

17.) „Gas storage and flow in coal-bed methane reservoirs Implementation of a bidisperse core model for gas diffusion in a coal matrix $\square$ by Ji-Quan Shi and Sevket Durucan, Imperial college, London http://www.spe.org/web/ejournals/REE/Apr05/SPE-84342-PA-P.pdf 18.) Garcia, A. (2004). “Development of production type curve for Coalbed methane reservoirs" MS thesis

19.) Manuel Arturo Sanchez (2004) “The impact of Stimulation on Production decline type curves for CBM wells” MS thesis, Petroleum and Natural Gas Engineering department, West Virginia University 20.) Efundem Ndipanquang Arrey (2004) “Impact of Langmuir Isotherm on Production behavior of CBM reservoir” MS thesis, Petroleum and Natural Gas Engineering department, West Virginia University

21.) Amol Bhaskar Bhavsar (2005) "Prediction of Coalbed methane reservoir performance with Type curves” MS thesis, Petroleum and Natural Gas Engineering department, West Virginia University

22.) Computer Modeling Group, Inc. (2003). “Tutorial: Building, running, and analyzing Coalbed methane model using Builder and GEM”.

23.) Aminian, K. (2005). "Type Curves for Production Prediction and Evaluation of Coalbed Methane Reservoirs,” SPE 97957, 2005 SPE Eastern Regional Meeting, Morgantown, WV 